\title{
AGUSTÍN SANZ Y FRANCISCO DE GOYA: EL PROYECTO DE REFORMA DEL PALACIO DE LOS DUQUES DE HÍJAR EN ZARAGOZA Y LA FALLIDA DECORACIÓN PICTÓRICA DE SU FACHADA (1773-1774)
}

\author{
Agustin Sanz and Francisco de Goya: the Reform Project \\ for the Palace of the Dukes of Hijar in Zaragoza and the \\ Failed Pictorial Decoration of its Façade (1773-1774)
}

\author{
Javier MARTÍNEZ MOLINA ${ }^{1}$ \\ Universidad de Zaragoza \\ javimat@unizar.es
}

Fecha de recepción: 13/12/2014

Fecha de aceptación definitiva: 07/09/2015

RESUMEN: Este artículo trata sobre el proyecto concebido a finales de 1773 por el destacado arquitecto aragonés Agustín Sanz Alós para la reforma de la fachada y las principales estancias de la planta noble del Palacio de los Duques de Híjar en Zaragoza, proyecto al que incorporó a su buen amigo Francisco de Goya para que se encargara de la decoración de la fachada con pinturas murales. En este escrito se estudian aspectos tales como: la historia previa del inmueble, su rehabilitación parcial por parte de Sanz, el proceso del encargo y diseño del proyecto de reforma del edificio, o el devenir posterior del inmueble hasta la actualidad. El proyecto de reforma de Agustín Sanz, incluida la participación fallida de Francisco de Goya en el mismo, también se analiza e interpreta desde un punto de vista artístico.

1. Dejo constancia aquí de mi agradecimiento al Dr. Arturo Ansón Navarro por sus clarificadores consejos y apreciaciones para la realización de este artículo. 
AGUSTÍN SANZ Y FRANCISCO DE GOYA: EL PROYECTO DE REFORMA DEL PALACIO DE LOS DUQUES DE HÍJAR...

Palabras clave: Agustín Sanz; Francisco de Goya; arquitectura; pinturas murales; Ilustración; Barroco clasicista.

ABSTRACT: This paper concerns the project conceived at the end of 1773 by the well-known Aragonese architect Agustín Sanz Alós for the reform of the façade and the most important rooms of the main floor of the Palace of the Dukes of Hijar in Zaragoza, a project in which his good friend Francisco de Goya was included in order to decorate the façade with mural paintings. The paper addresses aspects such as the previous history of the building, its partial rehabilitation by Sanz, the ordering and design process of the reform project of the building, or the later evolution of the building until present day. The reform project of Agustín Sanz, including the failed participation of Francisco de Goya, is also analysed and interpreted from an artistic viewpoint.

Key words: Agustín Sanz; Francisco de Goya; Architecture; Mural paintings; Enlightenment; Classical Baroque.

\section{INTRODUCCIÓN}

Al comienzo del otoño de 1773 Agustín Sanz Alós (1724-1801) estaba en un momento clave de su carrera profesional como arquitecto, en un periodo de crecimiento imparable tanto en encargos como en fama que tendría su colofón en mayo de 1775 con la obtención del título de Académico de Mérito de la Real Academia de Bellas Artes de San Fernando, distinción que lo convirtió en el profesional de la arquitectura de mayor rango de Aragón junto al pronto malogrado Gregorio Sevilla, inaugurando su etapa creativa de esplendor, y que le abrió las puertas de más de un cuarto de siglo de dominio casi indiscutible del panorama arquitectónico aragonés. En 1773, tras once años como maestro de obras con taller propio abierto en la ciudad (no obstante, la titulación gremial la poseía desde 1757 aproximadamente), Sanz era ya el arquitecto más prestigioso y respetado de Zaragoza. En esos once años como maestro independiente, que habían estado precedidos de una sólida formación previa, tanto teórica como práctica, y del trabajo como oficial de primer nivel en las obras de la Santa Capilla del Templo del Pilar entre 1754 y 1762 a las órdenes de su proyectista, el célebre Ventura Rodríguez, y de los directores de la obra, Julián Yarza Ceballos y Francisco Velasco, había logrado labrarse una sólida y merecida fama de profesional solvente, eficaz, fiable y muy renovador estéticamente, lo que le había valido el apoyo de las clases altas de la ciudad, sobre todo de la nueva burguesía ilustrada, algunos de cuyos miembros más prominentes habían comenzado a confiarle sus proyectos arquitectónicos más relevantes desde mediados de la década de 1760 (Francisco Destre, Juan Martín de Goicoechea, Simón Ignacio Tarazona...). El prestigio adquirido le permitió también la obtención de numerosos empleos públicos vinculados a la arquitectura a caballo entre la parte final de la década de 1760 y los 
primeros años de la de 1770, empleos que le proporcionaron ingresos regulares que facilitaron su asentamiento y crecimiento profesional progresivo y la posibilidad de acometer proyectos cada vez más ambiciosos. Entre ellos cabría destacar el de Maestro de Obras y Visor del Ayuntamiento de Zaragoza, el de Maestro de Obras de la Junta de Real Contribución de Zaragoza, pero, sobre todo, el de Arquitecto de referencia de la Intendencia General de Aragón, que le proporcionó muchos encargos públicos de cierta envergadura² [fig. 1].

2. Véanse las últimas aportaciones sobre Agustín Sanz en SERRANO MARTín, Eliseo. "Agustín Sanz (1724-1801), arquitecto del Duque de Híjar». En CASAus Ballester, M. ${ }^{a}$ José (Coord). Actas de las Jornadas sobre: El Señorío Ducado de Híjar. Teruel: Ayuntamiento de Híjar y Centro de Estudios del Bajo Martín, 2007, pp. 293-319; MARTínez Molina, Javier. "Agustín Sanz, un arquitecto ilustrado al servicio del poder señorial». En MarTínez Molina, Javier; Ortiz Cruz, Demelsa y Uliaque Arruego, Isabel. Cuadernos del Ducado de Híjar 1: El Legado Cultural. Teruel: Archivo Ducal de Híjar-Archivo Abierto y Centro de Estudios del Bajo Martín, 2008, pp. 69-98; MARTínez MolinA, Javier. "La nueva Iglesia de la Natividad de Nuestra Señora de La Puebla de Híjar: la intervención del arquitecto ilustrado zaragozano Agustín Sanz (1765-1772)». Artigrama, 2008, 23, pp. 539-564; MarTínEz Molina, Javier. "Nuevas aportaciones al estudio de la Puerta del Carmen de Zaragoza (1787-1795)». Artigrama, 2009, 24, pp. 443-466; MARTínEZ MolinA, Javier. «El Cuartel de Convalecientes de Zaragoza (1792-1799), un ejemplo de domus militaris de la época de la Ilustración». Artigrama, 2010, 25, pp. 465-490; MARTínez MolinA, Javier. "La Iglesia de la Exaltación de la Santa Cruz de Zaragoza, obra de Julián Yarza Ceballos y Agustín Sanz (1769-1780)". Academia. Boletín de la Real Academia de Bellas Artes de San Fernando, 2011, 112-113, pp. 115-151; MARTínEZ MOLINA, Javier. «Las cinco Casas en hilera para quiñoneros y el Oratorio de San Antonio de Padua del Monte del Ceperuelo de Híjar (1771-1775), obra del arquitecto ilustrado zaragozano Agustín Sanz». Rujiar, 2012, 13, pp. 183-204; MARTínez MolinA, Javier. "El Horno de cocer pan de Urrea de Gaén (1769-1771), un destacado edificio utilitario de la época de la Ilustración diseñado por el arquitecto zaragozano Agustín Sanz». Rujiar, 2012, 13, pp. 205-221; MARTínez MolinA, Javier. "La Casa-palacio de Simón Ignacio Tarazona en Zaragoza (1770-1771), obra del arquitecto ilustrado Agustín Sanz». Artigrama, 2012, 27, pp. 475-496; MARTínez Molina, Javier. "Juan Bautista Casabona, un indiano en la Zaragoza de la Ilustración: estudio de su casa-palacio (1768-1769), obra del arquitecto Agustín Sanz". Cuadernos de Estudios del Siglo XVIII, 2013, 23, pp. 101-128; MarTínEZ MolinA, Javier. "Noticias sobre dos proyectos de arquitectura civil de Agustín Sanz al servicio de la Casa de Híjar: la rehabilitación y ampliación del Horno de La Puebla de Híjar (1767-1768) y la nueva Casa del administrador de Samper de Calanda (1771-1772)». Rujiar, 2013, 14, pp. 223-232; MARTínez MolinA, Javier. "Los proyectos no construidos para la conclusión de la torre campanario de la Iglesia de la Natividad de Nuestra Señora de La Puebla de Hijar (1772-1784), obra de Agustín Sanz y Joaquín Cólera». Rujiar, 2013, 14, pp. 233-280; MARTínez MolinA, Javier. «Dos proyectos arquitectónicos de Agustín Sanz para la ciudad de Borja: la Casa mesón municipal (1786-1803) y la nueva Puerta de San Francisco (17911796)». Cuadernos de Estudios Borjanos, 2014, 57, pp. 95-148; MARTínez Molina, Javier. "Los retablos de la iglesia de la Natividad de Nuestra Señora de La Puebla de Híjar, obra de Francisco Sabatini, Joaquín Arali y Ramón Bayeu (1769-1771)». Boletín del Museo e Instituto Camón Aznar de Ibercaja, 2014, 112, pp. 117-184; y MARTínez Molina, Javier. La reforma neoclásica de la Colegiata de Santa María de Borja y sus proyectos previos (1791-1831). Borja (Zaragoza): Centro de Estudios Borjanos e Institución «Fernando el Católico» (CSIC), 2015. 


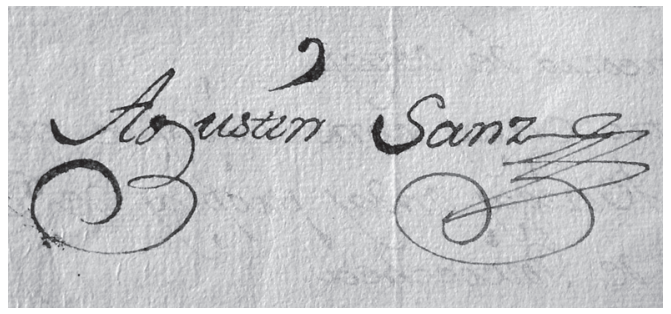

Figura 1. Firma del arquitecto Agustín Sanz de 1774 (AMZ, Serie Facticia, Caja 6, Sign. 12).

Entre los clientes particulares de Agustín Sanz destacó especialmente el IX Duque de Híjar, Pedro de Alcántara de Silva Fernández de Hijar y Abarca de Bolea (1741-1808) ${ }^{3}$, que lo convirtió en su arquitecto de referencia en Aragón y que sin duda fue el mejor y más constante comitente privado que tuvo Sanz a lo largo de toda su carrera. La relación entre ambos se había iniciado a principios de 1765, cuando el duque encomendó al arquitecto zaragozano la supervisión general de las obras de la Iglesia parroquial de La Puebla de Hijar (Teruel), y se prolongó por espacio de 36 años, hasta el fallecimiento de Sanz el 25 de julio de 1801. Durante ese periodo de tiempo tan largo, el ilustre aristócrata, muy aficionado a la arquitectura, encargó a Sanz el diseño de multitud de edificios para sus señoríos aragoneses, tanto de gran envergadura y empaque, como las Iglesias parroquiales de Urrea de Gaén y Vinaceite (que Sanz no solo diseñó sino que también construyó con su taller entre finales de la década de 1770 y principios de la de 1780 dentro de un refinado y exquisito lenguaje barroco clasicista ya muy depurado), como de carácter menor, siendo muy numerosos los encargos de edificios de carácter utilitario relacionados con la obtención de rentas señoriales (monopolios señoriales), como: molinos aceiteros, hornos de cocer pan, posadas, acequias, casas para colonos etc., pero también capillas, cárceles, un hospital o incluso un pueblo entero de nueva colonización... ${ }^{4}$ [fig. 2].

3. Véase una breve aproximación a la biografía del IX Duque de Híjar en MARTínez MOLINA, Javier. El Conjunto Palaciego de los Condes de Aranda en la villa de Épila. Zaragoza: Institución "Fernando el Católico» (CSIC), 2010, p. 42. Véanse más datos sobre el personaje en varios escritos de la Dra. M. a José Casaus Ballester, gran estudiosa de la historia de la Casa Ducal de Hijar: CASAus BALLESTER, M. ${ }^{a}$ José. Archivo Ducal de Híjar. Catálogo de los Fondos del antiguo Ducado de Híjar (1268-1919). Valencia: Diputación General de Aragón e Instituto de Estudios Turolenses, 1997, pp. 251-252; y CASAUS Ballester, M. a José. La pinacoteca de la Casa Ducal de Hijar en el siglo XIX. Nobleza y coleccionismo. Zaragoza: Institución «Fernando el Católico» (CSIC), 2006, pp. 15-16 y 122.

4. Véanse las últimas aportaciones sobre este tema en MARTínEZ MOLINA, Javier. La nueva Iglesia de la Natividad..., op. cit., pp. 539-564; MARTínez Molina, Javier. Las cinco Casas en hilera..., op. cit., pp. 183-204; y MarTínez Molina, Javier. El Horno de cocer pan..., op. cit., pp. 205-221. 


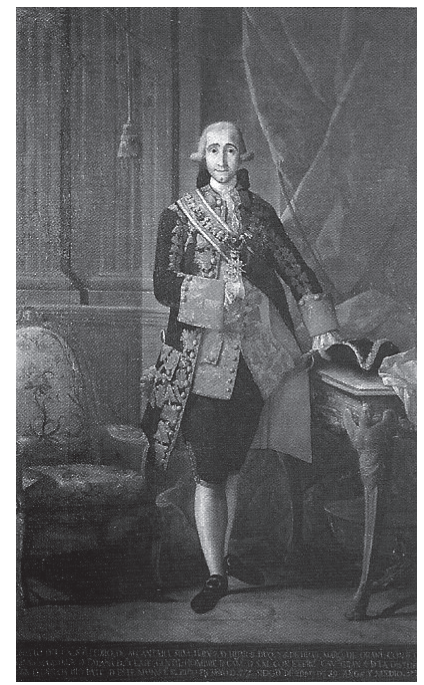

Figura 2. Retrato de Pedro de Alcántara de Silva Fernández de Híjar, IX Duque de Híjar. Antonio González Velázquez, 1774. Óleo sobre lienzo, 222 x 139 cm. Sevilla, Palacio de Dueñas.

De los encargos que recibió Agustín Sanz del IX Duque de Híjar en la primera mitad de la década de 1770 destaca uno que le encomendó a principios del otoño de 1773, consistente en la rehabilitación parcial del Palacio de los Duques de Hijar en Zaragoza, edificio que se ubicaba en la amplia calle del Coso, a decir del abate Ponz la mejor calle que hay en Zaragoza por su longitud, anchura y edificios que en ella se encuentran ${ }^{5}$, concretamente en el tramo perteneciente a la Parroquia de San Gil, casi enfrente del Palacio de los Condes de Sástago, en el n. ${ }^{\circ} 14$ (n. ${ }^{\circ} 29$ actual), que era una de las zonas más concurridas y bulliciosas de la ciudad y sin duda la más aristocrática al concentrar en muy pocos metros algunos de los mejores palacios de Zaragoza, pertenecientes a los más antiguos linajes del viejo Reino de Aragón. Muy poco tiempo después, el duque hizo extensivo el encargo a la concepción y diseño de la reforma de la fachada principal y de la zona noble del palacio, labor a la que Sanz incorporó a su buen amigo Francisco de Goya y Lucientes (1746-1828). Dichos proyectos tenían como objetivo la actualización y mejora funcional y estética de este magnífico inmueble, que estaba algo deteriorado a raíz de la falta de uso continuo por parte de los Duques de Híjar, que residían en Madrid y apenas visitaban Zaragoza, dentro de los parámetros estéticos y de confort propios de la época de la Ilustración [figs. 3 y 4].

5. Ponz, Antonio. Viage de España. Tomo XV ("Trata de Aragón»). Madrid: Imprenta de la Viuda de Ibarra, 1788, p. 90. 
AGUSTÍN SANZ Y FRANCISCO DE GOYA: EL PROYECTO DE REFORMA DEL PALACIO DE LOS DUQUES DE HÍJAR...

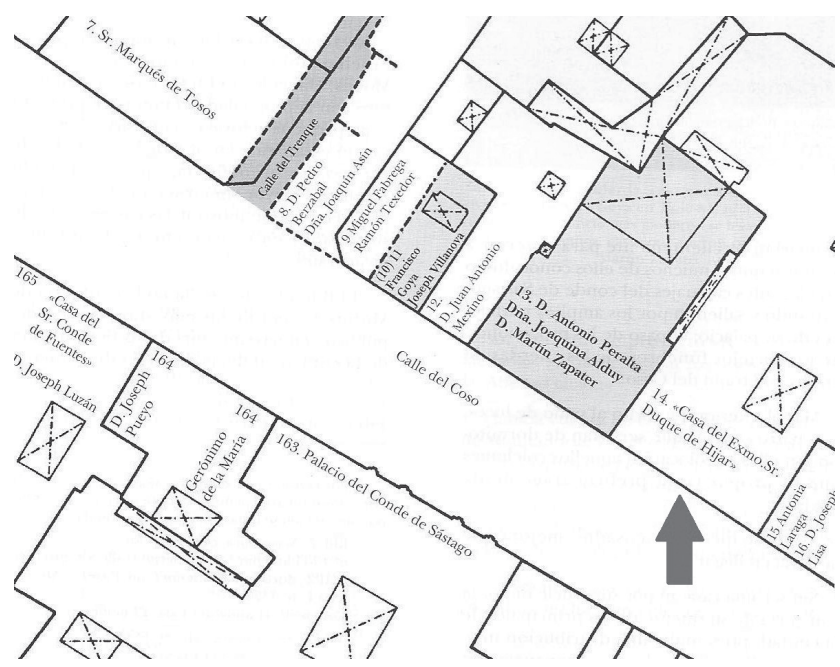

Figura 3. Detalle de un plano parcelario de Zaragoza en el que se observa la ubicación del Palacio de los Duques de Híjar (extremo derecho). Aparecen indicados los vecinos que ocupaban las casas colindantes al palacio en 1780-1781, pocos años después de su reforma (plano realizado por José Luis Ona a partir del Plano Parcelario de Zaragoza de Dionisio Casañal de 1911. Tomado de Ona González, José Luis. Goya y su familia en Zaragoza. Nuevas noticias biográficas. Zaragoza: Institución «Fernando el Católico», 1997, p. 295).

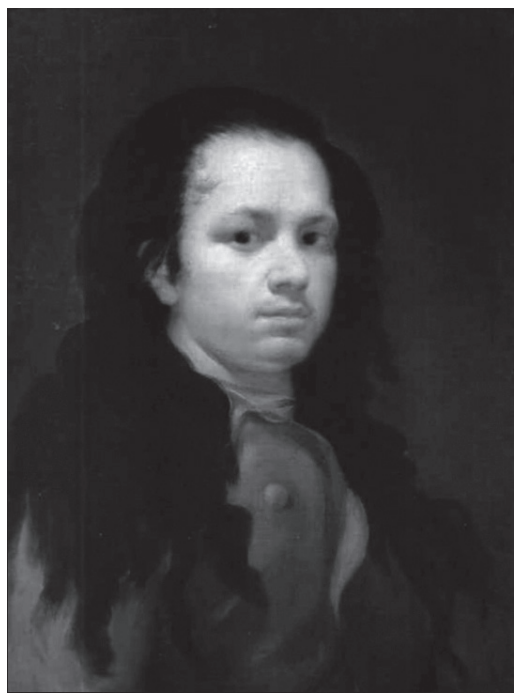

Figura 4. Autorretrato. Francisco de Goya y Lucientes, h. 1775. Óleo sobre lienzo, $59 ’ 6$ x $44^{\prime} 6 \mathrm{~cm}$. Zaragoza, Museo Goya-Colección Ibercaja. 
AGUSTÍN SANZ Y FRANCISCO DE GOYA: EL PROYECTO DE REFORMA DEL PALACIO DE LOS DUQUES DE HÍJAR...

\section{El Palacio de los Duques de Híjar en Zaragoza: los orígenes del edificio}

Cuando se encomendó a Agustín Sanz la intervención en el Palacio de los Duques de Híjar, el inmueble tenía ya casi dos siglos y medio de historia. Por su carácter pionero y su magnificencia, era una de las piezas más destacadas de la arquitectura civil renacentista en Aragón. Había sido construido en varias fases durante el primer tercio del siglo XVI por encargo fundamentalmente de Juan Francisco Pérez de Coloma y Calvillo, Secretario del Consejo Real, de ahí que se conociera como Casa de Coloma, siendo la última y más destacada la que se desarrolló entre 1528 y 1535, que fue ejecutada por el maestro de casas morisco Juan de Lanuza, aunque participaron también otros artífices. Así, durante la última fase de obras se labró e instaló el gran patio renacentista de cantería, que todavía en el último tercio del siglo XVIII era uno de los más suntuosos de la ciudad, cuya autoría se debió, según Carmen Gómez Urdáñez, al piedrapiquero Gil Morlanes, que probablemente se había encargado también, aunque en una etapa anterior, de la magnífica y renovadora portada del palacio $^{6}$, inspirada a mi juicio en uno de los arcos de triunfo romanos más célebres, el Arco de Tito de Roma, y en ciertos detalles del Arco de Constantino, también de Roma. No obstante, dicha inspiración debió de llegar de forma indirecta, probablemente a través de la portada de un palacio valenciano coetáneo, el de Jerónimo Vich, como señaló Carmen Gómez [fig. 5].

En la fase final de obras también se talló el magnífico alero de madera del patio por los mazoneros franceses Rubert Flori y Gamin Coquier, que a su vez se encargaron de hacer numerosas rosas y cruces de mazonería para varias techumbres que se habían instalado en una fase anterior y que probablemente se debieron al polifacético Juan de Lanuza. De los azulejos, que se concentrarían en las salas de verano de la planta baja, se encargó el maestro de probable procedencia alemana Cristóbal Vitver de Augusta, mientras que el mazonero de aljez Francisco de Santa Cruz

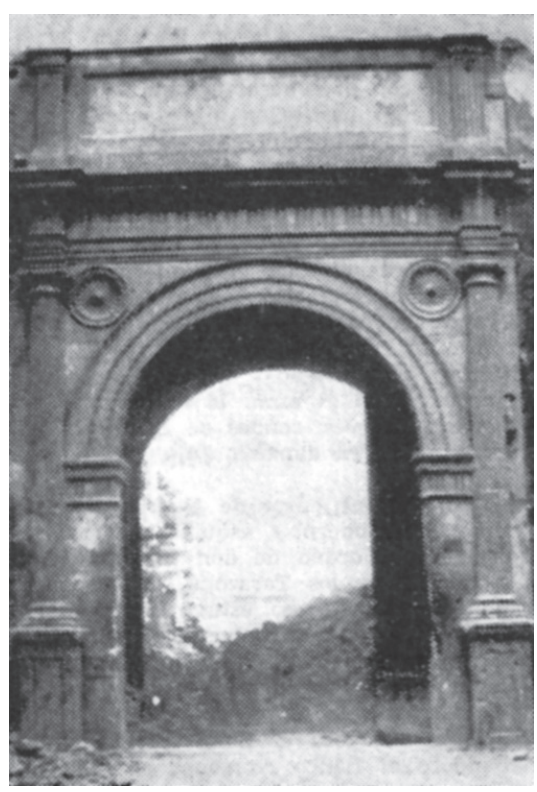

Figura 5. Vista de la magnífica portada renacentista del Palacio de los Duques de Híjar justo antes de su desmontaje en 1912.

6. Ibídem, p. 79. Sobre la construcción y características de la Casa de Coloma véase GómEz URDÁÑEZ, Carmen. Arquitectura civil en Zaragoza en el siglo XVI. Tomo I. Zaragoza: Ayuntamiento de Zaragoza, 1987, pp. 181-187. 
AGUSTÍN SANZ Y FRANCISCO DE GOYA: EL PROYECTO DE REFORMA DEL PALACIO DE LOS DUQUES DE HÍJAR...

tuvo a su cargo las numerosas aplicaciones ornamentales de yeso endurecido de portales, huecos y chimeneas, piezas que aportaron al inmueble un aspecto muy refinado. No obstante, la intervención artística más singular de la fase final fue la decoración pictórica de la gran fachada de la calle del Coso, que constituyó casi una excepción en la Zaragoza de la época y que se debió a un pintor forastero, Alonso de Villalpando. La fachada, con la excepción de la planta baja y la galería de arquillos de la falsa, quedó cubierta por unas pinturas murales cuya temática o características no se han podido establecer. Finalmente, con la realización de las labores de rejería y cerrajería, que se debieron a Guillem Garço, Pedro de Escalante, Pedro Barón, Francisco de Ariño y Juan Díez, se dieron por concluidas las obras del palacio, que se convirtió en uno de los mejores de la ciudad, consideración que mantuvo en los siglos posteriores, y que ejerció una gran influencia en la evolución y desarrollo de la arquitectura civil renacentista zaragozana ${ }^{7}$.

Con el transcurso de las décadas, los descendientes de Juan Francisco Pérez de Coloma se vieron obligados a vender el palacio a carta de gracia a Bernardino Pérez de Pomar, quien a su vez se lo vendió en 1608 al I Conde de Guimerá, Gaspar Galcerán de Castro Pinós, destacado erudito vinculado al círculo oscense de Vicencio Juan de Lastanosa, que lo convirtió en su residencia principal y que reunió en él una valiosa biblioteca y numerosas antigüedades. Por ello, el inmueble pasó a conocerse como Palacio de los Condes de Guimerá. A la muerte del conde sin descendencia en 1638, lo heredó, tras un largo pleito resuelto en 1663, su prima lejana Francisca de Castro Pinós Fenollet y Zurita, viuda del II Duque de Hijar, convirtiéndose desde entonces en el Palacio de los Duques de Hijar, es decir, en su residencia en Zaragoza en detrimento de la conocida como Casa del Condado de Belchite, ubicada en la calle de la Cuchillería (Don Jaime I), que hasta entonces les había servido como morada en la ciudad ${ }^{8}$.

3. La intervención de Agustín Sanz en el Palacio de los DuQues de Híjar: la REHABILITACIÓN PARCIAL DEL EDIFICIO Y EL PROYECTO DE REFORMA DE SU FACHADA Y DE LAS ESTANCIAS PRINCIPALES DE LA PLANTA NOBLE (1773-1774). LA PARTICIPACIÓN FALLIDA DE FRANCISCO DE GOYA EN EL PROYECTO DE REFORMA DE LA FACHADA

La intervención de Agustín Sanz en el Palacio de los Duques de Híjar en Zaragoza estuvo motivada en un principio por el importante deterioro que aquejaba al inmueble a comienzos de la década de 1770, que se hizo especialmente patente

7. Ibídem, pp. 181-187.

8. Blasco Ijazo, José. jAquí... Zaragoza!. Tomo 5. Zaragoza: Ayuntamiento de Zaragoza, 1954, pp. 35-37; y Moreno Meyerhoff, Pedro. "La Casa de Hijar: encrucijada de linajes». En CaSAus Ballester, M. a José (Coord). Jornadas sobre el Señorío-Ducado de Híjar: siete siglos de historia nobiliaria española. Teruel: Ayuntamiento de Hijar y Centro de Estudios del Bajo Martín, 2007, pp. 211-236, espec. pp. 222 y 226-227. La Casa Ducal de Hijar absorbió también otras propiedades y títulos del I Conde de Guimerá. 
a principios de septiembre de 1773 cuando el Administrador General de la Casa de Híjar en Aragón, José Faure y Oto, tomó la decisión de establecer su residencia en el propio palacio. Se instaló con su familia el 13 de septiembre y de inmediato encargó a Sanz la rehabilitación de los elementos que más urgían: una zona arruinada de la pared de la cochera, la entrada del salón principal, la escalera principal y su barandilla, la pared de la habitación (apartamento) de una inquilina, y parte de las últimas havitaciones de devajo del tejado, labores que ya se estaban acometiendo para el 28 de septiembre, fecha en que Faure escribió al IX Duque de Hijar para comunicárselo pero sobre todo para que autorizara otros trabajos adicionales de mayor envergadura que era necesario acometer sin dilación según el dictamen de Sanz, que había reconocido toda la casa. Le informó de la conveniencia de sacar las enrronas que se habían ido acumulando durante años en las caballerizas y bodegas, procedentes de distintas obras en el inmueble, y de abrir vías de ventilación en estos espacios para conserbar los maderos y precaber del salitre al edificio, que es el maior enemigo. También le expresó la necesidad de asentar y reforzar la pared maestra de la havitación principal que da al pozo mediante dos pilares encajados en la misma, pared que estaba muy dañada a consecuencia de la lluvia que incidía sobre ella a raíz del escaso vuelo del alero de su tejado. A su vez, era preciso hacer un refuerzo en la puerta falsa, ya que amenazaba ruina, y retejar el tejado. En cuanto a la carpintería exterior, según Agustín Sanz y Antonio Valero, maestro carpintero de la Casa Ducal de Hijar en Aragón, era necesario acometer una reparación de bastante calado, dado que habían hallado todas las puertas de los balcones de la planta noble eslaviadas y queradas, sin que una de ellas ajuste para libertar los suelos de la intemperie. No obstante, merecía la pena repararlas por ser muy costosas y hermosas y que pueden servir muchísimos años. Para ello era preciso poner fallebas enteras a dichas puertas y sus ventanos, con el fin de que cerraran bien, además de preservar las maderas de la intemperie, después de sustituir algunas podridas, dándoles un baño de cola y yeso blanco para que no penetrara el agua, dado que eran puertas-ventanas de paneles, distintas a las de la época, que eran enrrasadas y resistían más?.

Sin embargo, la obra que iba a tener un mayor coste por su complejidad y envergadura era la reparación en profundidad de las cuatro fachadas del primer piso del gran patio principal renacentista (las que quedaban a cubierto por sus cuatro galerías), ya que estaban en serio peligro de derrumbe por la apertura reciente de varias rejas y troneras para iluminar las cuadras que, en combinación con el número excesivo de puertas que se abrían en ellas, habían falseado los machones o pilares de ladrillo que servían para "atar» o estructurar dichas paredes, algunos de los cuales se habían abierto como una granada y señalan de cada día nuebas grietas. Para solucionar este grave problema, Sanz quería que los doce recibos o

9. Archivo Histórico Provincial de Zaragoza (AHPZ), Archivo Ducal de Híjar (ADH), Sala II, Leg. 147, Doc. 9.2. Respuestas a Su Excelencia, 1773 (Carta de 28-IX-1773). 
AGUSTÍN SANZ Y FRANCISCO DE GOYA: EL PROYECTO DE REFORMA DEL PALACIO DE LOS DUQUES DE HÍJAR..

refuerzos que era necesario acometer en los machones de las fachadas del patio se hicieran de ladrillo elegido, y sobre todo que se quitaran las rejas y troneras que dan luz por en medio de cada uno y es lo que les ha falseado, las cuales se recolocarían enrasadas en el suelo del patio, frente y en el promedio de cada puerta, lo que evitaría que se volvieran a dañar las paredes maestras. No obstante, dado que los cimientos no estaban dañados, no sería necesario calzar las cuatro fachadas con un zócalo general de piedra, sino simplemente utilizar ladrillo nuevo en las zonas rehechas. Como contrapartida, la gran cantidad de ladrillo de despojo que saldría de las viejas paredes se podría reaprovechar para obras menores. Para evitar derrumbes hasta que se iniciaran los trabajos, Sanz apuntalaría el patio ${ }^{10}$.

Antes de dar el visto bueno a todas estas obras, cuyo coste fue calculado por Agustín Sanz y Antonio Valero en unos 100 doblones $^{11}$, el Duque de Híjar mostró su contrariedad por el hecho de que el palacio no se hubiera ido reparando paulatinamente antes de llegar a un estado de deterioro tan grave, como debe hacerse y sucede con toda finca que se maneja a ley, y sobre todo mandó que Sanz trazara unos dibujos o diseños mostrando las principales intervenciones necesarias, así como un cálculo pormenorizado y desglosado de su coste, con el fin de informarse mejor sobre el asunto. Al poco, el 5 de octubre, Faure se excusó y justificó ante el duque señalando que siempre se había preocupado por la conservación de las dos casas-palacio que la Casa Ducal poseía en Zaragoza y que llevaba varios meses tratando con Sanz sobre la reparación de los machones del patio, cuya situación se había agravado muy recientemente, a la espera de que este hiciera un informe sobre el asunto, de ahí que no lo hubiera comunicado todavía. También le indicó que Sanz veía muy complicado elaborar dibujos de los reparos necesarios por la complejidad de representarlos sobre el papel, a diferencia del cálculo de su coste, que este ya estaba preparando para remitirlo de inmediato ${ }^{12}$.

Paradójicamente, solo dos semanas después, el 20 de octubre de 1773, el panorama cambió por completo, ya que el Duque de Híjar no solo dio su visto bueno a la ejecución de los reparos propuestos por Agustín Sanz tras aprobar su cálculo de costes, cifrado finalmente en 6.000 reales de vellón (319 libras jaquesas), reparos que debían acometerse con la solidez correspondiente, procurando la mayor economía, sino que, ante la dificultad de que Sanz dibujara los reparos necesarios y dado que a largo plazo sería preciso acometer reformas de calado en el palacio para actualizarlo y mejorarlo más allá de reparaciones más o menos profundas, decidió encargarle también la elaboración de un diseño con una propuesta de reforma de la fachada principal, que debía de estar muy deteriorada dado que, a diferencia de la mayoría de los palacios zaragozanos, presentaba su

10. AHPZ, ADH, Sala II, Leg. 147, Doc. 9.2. Respuestas a Su Excelencia, 1773 (Carta de 28-IX-1773).

11. La documentación no aclara el tipo de doblón del que se trataba, por lo que no se puede indicar la equivalencia en libras jaquesas ni reales de vellón.

12. AHPZ, ADH, Sala II, Leg. 147, Doc. 9.1. Cartas Órdenes del Señor Duque, 1773 (Carta de 2-X-1773). AHPZ, ADH, Sala II, Leg. 147, Doc. 9.2. Respuestas a Su Excelencia, 1773 (Carta de 5-X-1773). 
superficie enlucida y pintada, cubierta todavía probablemente por las pinturas murales de Alonso de Villalpando. También le encomendó la elaboración de un plano de la havitación principal, o lo que es lo mismo, la creación de diseños de los espacios más importantes de la planta noble, tanto públicos como privados (la sala o salón principal con su cámara y las estancias privadas de los duques), planteando en ellos su composición, es decir, una propuesta de redistribución, reforma y actualización estético-decorativa de estos espacios principales del palacio ${ }^{13}$.

Al poco tiempo, tras reponerse de un leve problema de salud, Agustín Sanz se puso a preparar los diseños que le había pedido el duque, y en paralelo su taller inició, bajo su dirección facultativa, las obras de rehabilitación del inmueble. Así, las trazas de Sanz ya estaban concluidas el 1 de enero de 1774, fecha en que José Faure las remitió a Madrid acompañadas de una carta suya, otra carta-informe del propio arquitecto explicando sus propuestas de reforma, así como una razón del importe de la cantería. En su carta, Faure puntualizó al duque un aspecto muy interesante: que Agustín Sanz le acababa de comunicar que había logrado convencer a su buen amigo Francisco de Goya, que llevaba dos años y medio residiendo y trabajando en Zaragoza tras regresar de su larga estancia formativa en Italia, para que pintara la fachada principal del palacio, sin duda con el fin de actualizarla no solo a nivel arquitectónico sino también pictórico ${ }^{14}$. Goya debía decorarla con unas nuevas pinturas murales «a la última moda" que sustituyeran a las viejas pinturas renacentistas de Alonso de Villalpando, que debían de estar ya muy deterioradas y desfasadas en todos los sentidos y que, además, tras la reforma de Sanz, no serían ya reaprovechables a consecuencia, entre otras cosas, de la modificación de huecos que padecería la fachada ${ }^{15}$. De esta manera, tal y como le

13. AHPZ, ADH, Sala II, Leg. 147, Doc. 9.2. Respuestas a Su Excelencia, 1773 (Carta de 23-X1773). AHPZ, ADH, Sala III, Leg. 107, Doc. 1. Respuestas a Su Excelencia, 1774 (Carta de 1-I-1774). AHPZ, ADH, Sala III, Leg. 107, Doc. 1. Cartas Órdenes del Señor Duque, 1774 (Carta de 31-VIII-1774).

14. Esta vinculación de Goya con el proyecto de reforma del Palacio de los Duques de Híjar, así como el propio proyecto de Sanz, eran inéditos hasta el momento.

15. A principios de la década de 1770, tras el asentamiento de Francisco de Goya en Zaragoza en el verano de 1771 al regreso de su larga estancia formativa en Italia (1769-1771), la relación entre este y Agustín Sanz era muy estrecha a pesar de su gran diferencia de edad, que era de 21 años y 3 meses (Sanz había nacido el 29-XII-1724 y Goya el 30-III-1746). Dicha relación se remontaba a la niñez de Goya, algo que manifestó Sanz al actuar como testigo de la libertad y soltería del pintor en el expediente matrimonial que este tramitó a mediados de 1773 para poder casarse con Josefa Bayeu. Indicó que conocía de vista y trato a dicho don Francisco Goya en Zaragoza [...] desde niño y que solamente había dexado de tratarle en ella los dos años que residió en Roma, algo que pudo deberse a una relación profesional con el padre del pintor, el dorador José Goya, lo que le habría llevado a tratar a los miembros de su familia. Que Goya eligiera a Sanz como uno de los tres testigos que debían acreditar su soltería en Zaragoza, un asunto muy delicado y personal, indica la estrecha amistad que le unía a él a mediados de 1773 , pocos meses antes de que le convenciera para decorar la fachada del Palacio de los Duques de Híjar. No obstante, la elección de Sanz pudo deberse también, pero solo como complemento de lo anterior, al deseo de Goya de sustentar la veracidad de su declaración de soltería en un profesional de prestigio como Sanz, que era ya el mejor arquitecto de la ciudad, 
AGUSTÍN SANZ Y FRANCISCO DE GOYA: EL PROYECTO DE REFORMA DEL PALACIO DE LOS DUQUES DE HÍJAR...

había indicado Sanz a Faure, la fachada quedaría en la devida perfección por ser este profesor de lo mejor que se halla, pues sobre su ingenio ha aprehendido mucho recorriendo la Ytalia y Francia. Es más, el Administrador General de la Casa de Hijar en Aragón planteó la cuestión como un auténtico logro, no solo por la calidad del artista (que siguiendo lo que le había dicho Sanz presentó como cuñado de don Francisco Bayeu, Pintor del Rey, que se halla acá), sino por el hecho de que este hubiera rehusado pintar poco antes las fachadas de varios edificios

algo que tiene sentido dado que otro de los testigos fue Carlos Salas, el escultor más destacado de la Zaragoza de la época. Es más, en la elección de ambos, además de las indudables razones de amistad y prestigio, pudo pesar también una voluntad clara de Goya de vincularse de forma explícita a los dos artistas más encumbrados de la Zaragoza del momento en los campos de la arquitectura y la escultura, consideración que el pintor pensaba que le correspondía a él en el ámbito de la pintura al tenerse por el mejor artista del panorama pictórico zaragozano (estaba desarrollando el gran ciclo pictórico de la Cartuja de Aula Dei y poco antes había pintado la bóveda del Coreto del Templo del Pilar).

La relación entre Agustín Sanz y Francisco de Goya se extendió también al ámbito profesional, habiendo sido aquel uno de los primeros en percatarse de la gran valía de Goya como pintor, lo que explica que quisiera incorporarlo muy tempranamente, a pesar de su relativa juventud, a algunos de sus proyectos arquitectónicos más destacados de principios de la década de 1770, encargándole (o tratándole de encargar) obras como: la decoración de la fachada principal de la Casa-palacio de Simón Ignacio Tarazona en 1771, la ornamentación del Oratorio del Palacio de los Condes de Sobradiel en 1772 (que a mi juicio acometió por mediación de Sanz, autor probable de los diseños para la reedificación del edificio), o la decoración de la fachada del Palacio de los Duques de Híjar en 1773-1774. Posteriormente, a pesar de la marcha de Goya a Madrid y su triunfo en la Corte, la relación entre ambos se mantuvo y, de hecho, Goya llegó a intervenir en algunas de las obras más destacadas de Sanz, como la Iglesia de Urrea de Gaén, que este diseñó para el Duque de Híjar en 1777 y que construyó entre 1778 y 1782, para la que el pintor realizó en 1782-1783 el lienzo del retablo colateral del lado del evangelio, dedicado a la Aparición de la Virgen del Pilar a Santiago y los Convertidos, aunque no se sabe si por mediación de Sanz o del escultor Joaquín Arali, autor de la mazonería de los retablos, o por deseo expreso del duque, que residía en Madrid y que además de conocer la valía de Goya se caracterizaba por proteger a los artistas aragoneses residentes en la Corte, aunque parece más factible lo último atendiendo al proceder del duque en casos similares como el de los lienzos para los tres altares principales de la Iglesia de Vinaceite, también diseñada por Sanz, que encargó directamente al también aragonés Ramón Bayeu. Además, en sus distintos viajes a Zaragoza, Goya siguió sin duda frecuentando a Sanz, sobre todo al tener grandes amigos en común, como Juan Martín de Goicoechea o Martín Zapater (Sanz era sin duda asistente asiduo a la tertulia que Zapater ofrecía en su casa, a la que acudía Goya cuando estaba en Zaragoza), y curiosamente, cuando vino a Zaragoza entre finales de 1780 y los primeros meses de 1781 para pintar en El Pilar, se alojó, por mediación de Zapater, en una casa ubicada en el Coso, frente al Palacio de Sástago, que había reedificado el arquitecto unos quince años antes para el mancebo cirujano José Casanova, que arrendó una habitación o apartamento dentro de la misma al pintor y su familia. Como anécdota que demuestra la pervivencia en el tiempo de la relación entre Sanz y Goya, cabe resaltar el hecho, ya reseñado por Arturo Ansón, de que este se encargara de comprar a aquel en Madrid papel y otros materiales de dibujo difíciles de encontrar en Zaragoza. Véase López OrTega, Jesús. "El expediente matrimonial de Francisco de Goya». Boletín del Museo del Prado, 2008, XXVI, 44, pp. 62-68, espec. pp. 63-64 y 67-68; MARTínez Molina, Javier. La Casa-palacio de Simón Ignacio..., op. cit., p. 481 y 486-488; Ansón Navarro, Arturo. Goya y Aragón. Familia, amistades y encargos artísticos. Zaragoza: Caja de Ahorros de la Inmaculada, 1995, pp. 142145 y 161-162; y ONA GONZÁLEZ, José Luis. Goya y su familia en Zaragoza. Nuevas noticias biográficas. Zaragoza: Institución «Fernando el Católico» (CSIC), 1997, pp. 109-116 y 293-300. 


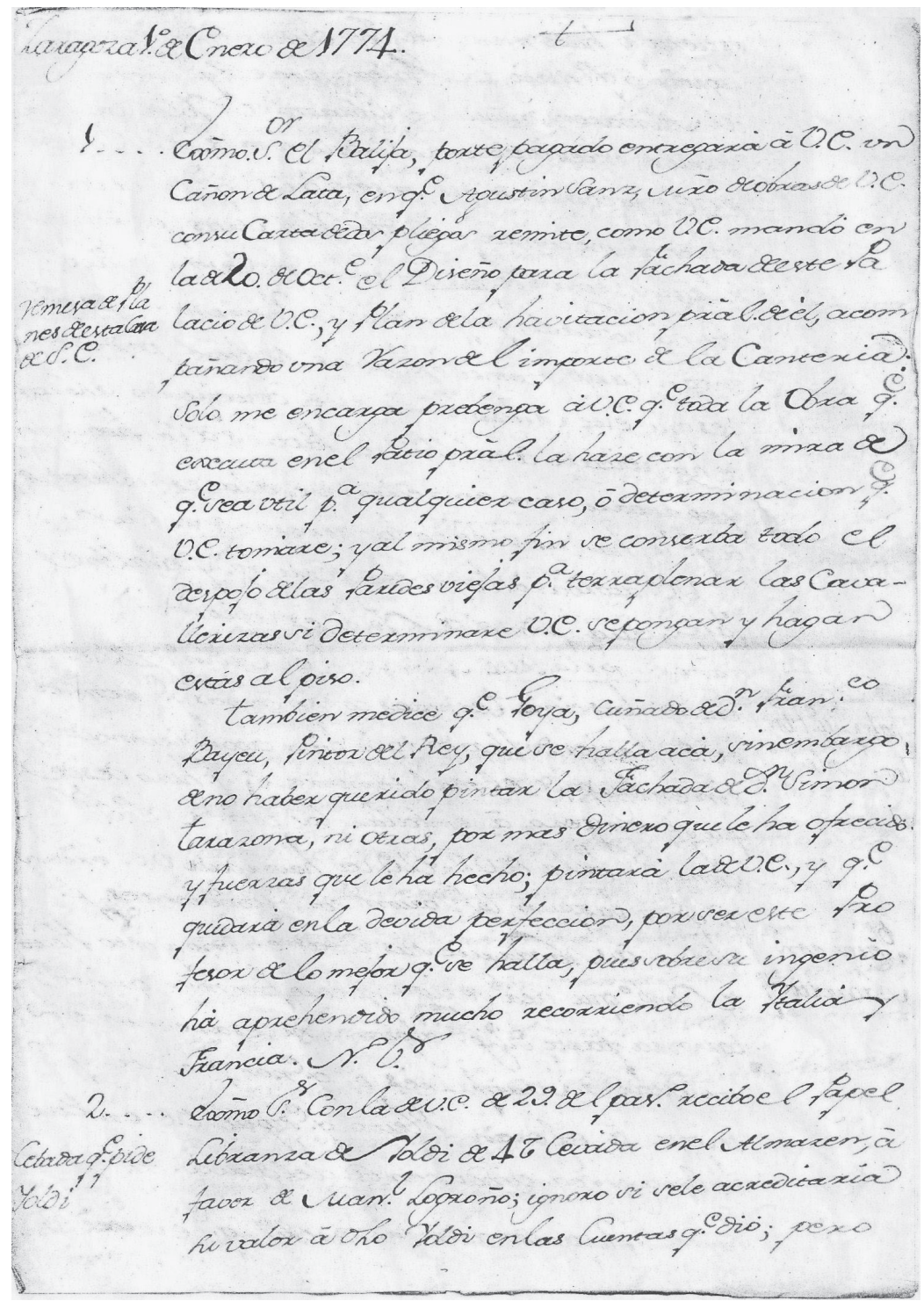

Figura 6. Carta del administrador José Faure, fechada el 1 de enero de 1774, en la que informa al IX Duque de Hijar del envío adjunto de los diseños elaborados por Agustín Sanz para la reforma del palacio ducal de Zaragoza y de que este había logrado convencer a su buen amigo Francisco de Goya para que pintara la fachada principal de dicho palacio (AHPZ, ADH, Sala III, Leg. 107, Doc. 1. Respuestas a Su Excelencia, 1774. Carta de 1-I-1774). 
proyectados por Sanz a pesar de la importancia de sus propietarios y de la amistad que le unía al arquitecto, siendo buen ejemplo de ello la magnífica Casa-palacio de Simón Ignacio Tarazona, cuya amplia fachada no quiso decorar por más dinero que le ha ofrecido y fuerzas que le ha hecho, sin duda al considerar el tipo de encargo, una pintura mural de fachada, más propio de un pintor-decorador que de un auténtico artista con altas aspiraciones ${ }^{16}$, lo que daba especial valor a que hubiera querido pintar la del palacio ducal, algo no obstante entendible atendiendo a la enorme relevancia del cliente y su gran influencia en la Corte, dado que de quedar satisfecho podría abrirle numerosas puertas en un futuro. Por otro lado, en cuanto a la rehabilitación del patio principal del palacio, que estaba en plena ejecución, Faure indicó al duque que Sanz la acometía con la vista puesta en que fuera útil para cualquier decisión que se tomara más adelante, de ahí que, entre otras cosas, estuviera conservando el despojo de las paredes viejas para poder terraplenar las caballerizas en caso de que se decidiera hacerlas nuevas en la planta calle ${ }^{17}$ [figs. 6 y 7 ].

Poco después, el 5 de enero de 1774, el Duque de Hijar acusó el recibo de los diseños de Agustín Sanz y la documentación vinculada, pero quedó en tomar una decisión sobre su puesta en ejecución a su tiempo, probablemente a la conclusión de las obras de rehabilitación del inmueble, que seguían en marcha y que se terminaron hacia finales de agosto con la vista puesta en que sirvieran de punto de partida a una intervención mucho más ambiciosa. De hecho, el 27 de agosto de 1774 Faure informó al duque de que dichas obras habían tenido un coste final de 887 libras jaquesas (16.696 reales de vellón), muy superior al inicialmente previsto, lo que despertó su enojo, ya que no había sido informado previamente del desfase en el que se estaba incurriendo ni lo había autorizado. Es más, reprendió severamente a su administrador y le exigió que le remitiera las cuentas pormenorizadas de dichas obras. El 5 de septiembre, Faure, que estaba fuera de Zaragoza, se comprometió a enviarlas a su regreso a la ciudad y le aseguró que solo se habían hecho los reparos precisos con la maior solidez y economía, siendo lo que más ha importado el recibo de los 12 machones que sostienen el patio principal, cuias quatro fachadas o paredes se benian a tierra por lo clugido de ellas y falta de cimientos. Es más, le puntualizó que buena parte del desfase

16. Esta actitud deja bien patente la alta consideración que como artista tenía de sí mismo Francisco de Goya en una época todavía muy temprana de su carrera, lo que le llevaba a renunciar a encargos que consideraba de carácter menor o poco adecuados para un pintor de su categoría.

17. AHPZ, ADH, Sala III, Leg. 107, Doc. 1. Respuestas a Su Excelencia, 1774 (Carta de 1-I-1774). En lo referente a Goya, en esta carta Faure señaló lo siguiente: También me dice [Agustín Sanz] que Goya, cuñado de don Francisco Bayeu, Pintor del Rey, que se halla acá, sin embargo de no haber querido pintar la fachada de don Simón Tarazona, ni otras, por más dinero que le ba ofrecido y fuerzas que le ha hecho, pintará la de Vuestra Excelencia y que quedará en la devida perfección por ser este profesor de lo mejor que se halla, pues sobre su ingenio ha aprehendido mucho recorriendo la Ytalia y Francia. 


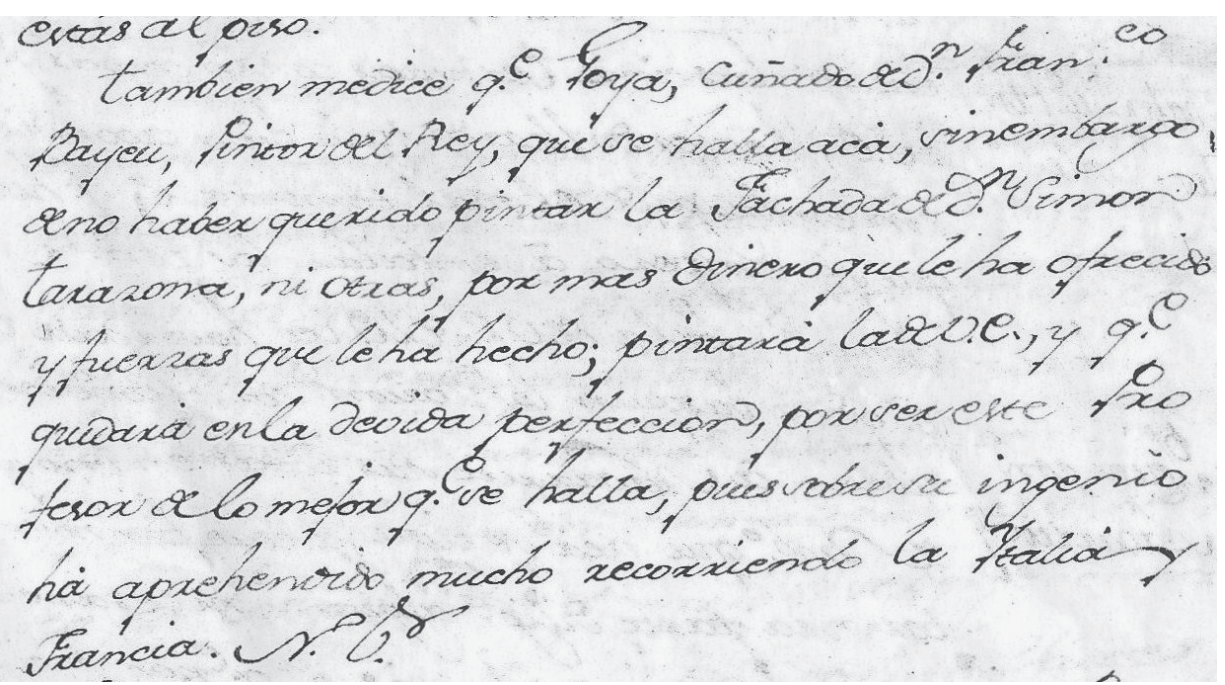

Figura 7. Detalle de la carta del administrador José Faure del 1 de enero de 1774 en la que se aprecia el párrafo en el que este indica al IX Duque de Híjar que Agustín Sanz había logrado convencer a Francisco de Goya para que pintara la fachada principal del palacio ducal (AHPZ, ADH, Sala III, Leg. 107, Doc. 1. Respuestas a Su Excelencia, 1774. Carta de 1-I-1774).

se había debido a que Sanz se había visto obligado a rehacer muchos cimientos que aparentemente estaban en buen estado, algo que no había podido prever, y a traher a juego y fortificar las puertas y ventanas, lo que había conllevado que los carpinteros tuvieran que asistir a las obras de manera continua. Finalmente, el 11 de octubre Faure remitió al duque las cuentas de las obras y los diez recibos de Agustín Sanz y Antonio Valero que acreditaban las distintas partidas que se les habían abonado. El duque le contestó el 19 de octubre y quedó en dar nuevas instrucciones tras estudiar la documentación ${ }^{18}$.

Lamentablemente, las importantes lagunas del Archivo Ducal de Hijar impiden determinar fehacientemente que ocurrió después, aunque todo parece indicar que la intervención de reforma ideada por Agustín Sanz sí que llegó a ponerse en práctica, por lo menos parcialmente, a pesar del enojo inicial del duque por el desfase de la rehabilitación, dada la precaria situación en que seguía el inmueble, que simplemente se había logrado salvar de la ruina, y teniendo en cuenta el gusto y la preocupación especial del IX Duque de Híjar por la arquitectura y por

18. AHPZ, ADH, Sala III, Leg. 107, Doc. 1. Cartas Órdenes del Señor Duque, 1774 (Cartas de 5-I-1774, 31-VIII-1774, 19-X-1774). AHPZ, ADH, Sala III, Leg. 107, Doc. 1. Respuestas a Su Excelencia, 1774 (Cartas de 8-I-1774, 5-IX-1774, 11-X-1774). 
AGUSTÍN SANZ Y FRANCISCO DE GOYA: EL PROYECTO DE REFORMA DEL PALACIO DE LOS DUQUES DE HÍJAR...

la buena conservación y aspecto de los edificios que le pertenecían o estaban a su cargo, sobre todo de aquellos inmuebles que de manera especial proyectaban su imagen pública. No obstante, la reforma del edificio se debió de retrasar algo, probablemente hasta 1775-1776, una época muy propicia para acometer dichas obras a consecuencia de la notable liquidez de la que disponía la Casa Ducal de Híjar en aquel periodo como resultado de varios años de buenas cosechas y de bonanza económica general que habían llenado sus arcas. Por el contrario, una fecha más allá de 1777 parece menos probable dado que en los últimos meses de ese año se pusieron en marcha los proyectos de construcción de las Iglesias de Urrea de Gaén y Vinaceite, también a cargo de Agustín Sanz, que concentraron el esfuerzo inversor de la Casa Ducal durante varios años, hasta entrada la década de $1780^{19}$. A mi juicio no hay duda de que la reforma del palacio se llegó a acometer, por lo menos en lo referente a la fachada principal, dado que a finales del siglo XIX su aspecto correspondía plenamente, en cuestiones como su configuración de huecos, a los usos arquitectónicos propios del último tercio del siglo XVIII, habiéndose eliminado destacados elementos originales del siglo XVI como la galería de arquillos superior ${ }^{20}$. No obstante, lo que sí quedó en el tintero irremediablemente fue la idea inicial de que Francisco de Goya decorara la fachada principal del palacio con pinturas murales, ya que el 3 de enero de 1775 , fecha en la que todavía no se había iniciado la reforma proyectada por Sanz ${ }^{21}$, el pintor aragonés marchó de Zaragoza, una vez concluidas las pinturas murales de la Cartuja de Aula Dei, en vista de que el inicio de la reforma del palacio del duque se demoraba en exceso y de que le habían surgido nuevos horizontes profesionales en la Corte. De hecho, marchó para instalarse en Madrid, a donde había sido llamado por el

19. No obstante, tampoco es descartable que el proyecto de reforma se acometiera avanzada la década de 1780, una vez concluida la construcción de ambos templos, aunque parece menos probable dado que para entonces las arcas de la Casa Ducal estaban ya bastante exhaustas, a lo que se añade que la reforma del palacio no se menciona en la correspondencia cursada entre el duque y sus administradores que se conserva del periodo 1783-1805 (aunque este dato no es concluyente, ya que, como ocurrió en otros casos, de existir cartas, estas pudieron entresacarse de la correspondencia general y agruparse en un legajo propio, hoy perdido, para ser archivadas conjuntamente).

20. También cabe la posibilidad, aunque mucho más improbable, de que la clasicista y austera fachada visible en fotografías de finales del siglo XIX y principios del XX no correspondiera al proyecto de reforma de Agustín Sanz sino a otro acometido durante la primera mitad del siglo XIX, cuando el palacio ya no pertenecía a la Casa de Híjar, dado que en dicho periodo estuvieron vigentes en la arquitectura civil aragonesa unas pautas estéticas muy vinculadas todavía a la tradición arquitectónica clasicista codificada en la época de la Ilustración y por tanto muy relacionadas con aquellas soluciones que Sanz pudo plantear en su proyecto de finales de 1773. Por ello, un hipotético proyecto muy posterior, de la primera mitad del siglo XIX, tendría todavía sin duda grandes paralelismos con el proyecto de Sanz.

21. Me baso en que no se hace mención al inicio de las obras de reforma de la fachada en las cartas cruzadas entre el Duque de Híjar y su administrador José Faure en el año 1774. La correspondencia general entre 1775 y 1782 no se conserva. Véase AHPZ, ADH, Sala III, Leg. 107, Doc. 1. Cartas Órdenes del Señor Duque, 1774 y Respuestas a Su Excelencia, 1774. 
primer Pintor de Cámara, Anton Rafael Mengs, con el fin de que trabajara como ayudante suyo en la Real Fábrica de Tapices de Santa Bárbara ${ }^{22}$. De esta manera tan simple se frustró la que hubiera sido, en caso de haberse acometido, una obra única y singular dentro de la trayectoria del gran pintor aragonés, ya que nunca llegó a ejecutar pinturas murales de fachada, por lo menos que se sepa.

Posteriormente, Agustín Sanz volvió a intervenir en el inmueble, aunque casi todas fueron intervenciones de rango menor. Así, por ejemplo, el 8 octubre de 1779 redactó un informe reseñando varios reparos cuya ejecución consideraba muy urgente y que calculó en 3.760 reales de vellón (200 libras jaquesas), obras que el duque mandó que acometiera el propio taller de Sanz bajo su dirección, mientras que a finales de febrero de 1788 llevó a cabo el refuerzo de los machones que sostenían el medianil del palacio con la adyacente Casa de Alduy, en la que vivía Martín Zapater, buen amigo suyo y de Goya, obra cuyo coste calculó en 50 o 60 libras (entre 941 y 1.129 reales) ${ }^{23}$.

4. El Devenir posterior del Palacio de los Dugues de Híjar en Zaragoza (1805-2004)

La Casa Ducal de Hijar fue la propietaria del palacio hasta 1805, fecha en que el propio IX Duque, a pesar de las importantes mejoras acometidas a su costa en el inmueble, lo vendió a quien era su apoderado y administrador general en Aragón por aquel entonces y a la vez arrendatario de sus estados aragoneses, Vicente Goser y Casellas, natural de la localidad catalana de Calaf y afincado en Zaragoza desde hacía más de dos décadas, por 487.458 reales y 28 maravedís de vellón (25.897 libras jaquesas) en vales reales, un precio muy considerable que indica la gran categoría del edificio y el enorme poderío económico del comprador, que era uno de los miembros más prominentes de la burguesía mercantil zaragozana desde hacía años. Se dedicaba sobre todo al comercio de granos a gran escala, una lucrativa actividad que podía desarrollar al tener en arriendo algunos de los estados señoriales mas importantes del Reino de Aragón, como el Ducado de Híjar o los Condados de Aranda y Sástago ${ }^{24}$. La venta, que permitió a Goser hacerse con la propiedad de un inmueble de gran categoría con el que poder dejar patente

22. ANSÓn NAVArro, Arturo. Goya y Aragón..., op. cit., p. 118.

23. AHPZ, ADH, Sala 1, Leg. 477, Doc. 1 (Informe de 8-X-1779 y Pliego de 12-X-1779). AHPZ, ADH, Sala II, Leg. 32, Doc. 11 (Carta de 26-II-1788). En octubre de 1779 los reparos más urgentes que requería el palacio según Agustín Sanz eran construir la bóbeda que está arruinada y recibir los cimientos de una porción de la construida, que se allan falseados; formar un arco en el sótano para sostener la pared que dibide la sala principal frente al quarto de don Eugenio; a la bajada de las caballerizas se han de recibir las paredes que forman la caja de la escalera principal.

24. Sobre las actividades económicas de Vicente Goser y Casellas y su genealogía véase GómEz ZORRAQuino, José Ignacio. "La burguesía mercantil catalana y su presencia en Aragón (1770-1808)». Pedralbes. Revista de Historia Moderna, 1988, 8, 1, pp. 405-423. 
AGUSTÍN SANZ Y FRANCISCO DE GOYA: EL PROYECTO DE REFORMA DEL PALACIO DE LOS DUQUES DE HÍJAR...

la brillante posición económica y social alcanzada, tuvo como fin principal la redención de cargas de los Estados del Duque de Hijar y fue posible gracias a que el aristócrata ya no necesitaba el edificio al haber heredado las propiedades de su tío-yerno Pedro Pablo Abarca de Bolea, X Conde de Aranda, a su muerte en 1798, incluido su magnífico palacio zaragozano, la antigua Casa de Miguel Velázquez Climent, que también se ubicaba en el Coso pero en el tramo de la Parroquia de San Miguel, y que era similar al suyo aunque estaba mejor conservado ${ }^{25}$.

Tras el fallecimiento de Vicente Goser a finales de agosto de 1819, el antiguo Palacio de los Duques de Híjar pasó en usufructo a su viuda María Casellas, quien en 1820 se lo cedió, junto a otros bienes de la herencia, a su hijo Dámaso Goser y Casellas, que era el heredero universal de su padre. Dámaso Goser fue el propietario del inmueble hasta 1839, fecha en que se lo vendió a Agustín de Azara y Mata, III Marqués de Nibbiano, quien fijó en él su residencia, pasando a conocerse desde entonces como Palacio de los Marqueses de Nibbiano ${ }^{26}$. Posteriormente, el linaje de los Azara siguió ostentando la propiedad del inmueble hasta el 2 de julio de 1910, fecha en que fue adquirido, por 635.000 pesetas, por el Centro Mercantil, Industrial y Agrícola de Zaragoza, que ya lo ocupaba en régimen de alquiler desde 1875. Tras su compra, el edificio fue reformado en profundidad entre 1912 y 1914 según un proyecto del joven arquitecto Francisco Albiñana Corralé que conllevó el derribo de la fachada principal del inmueble (incluido su magnífico alero renacentista), que fue sustituida por la actual de estilo modernista, aunque

25. AHPZ, ADH, Sala V, Leg. 92/2, Doc. 3-1 (Copia de escritura de venta de 8-III-1805). La existencia de esta escritura fue dada a conocer por la Dra. M. ${ }^{a}$ José Casaus Ballester, véase CASAUS BALLESTER, M. ${ }^{a}$ José. "Consecuencias de la Guerra de la Independencia en el Ducado de Híjar: las Concordias de Bezares». Studium. Revista de Humanidades, 2008, 14, pp. 219-243, espec. p. 228. Curiosamente, el antiguo Palacio de los Condes de Aranda sirvió durante muy poco tiempo como morada zaragozana de los Duques de Híjar ya que fue parcialmente destruido durante los Sitios franceses de Zaragoza de 1808-1809. Posteriormente fue convertido en viviendas. En la actualidad no se conserva, aunque en la reciente construcción de un hotel en parte de su antiguo solar aparecieron algunos restos (columnas del patio...).

26. Archivo Municipal de Zaragoza (AMZ), Caja 7277, Sign. 42, Catastro 1768-1848, Letras T-V, ficha 87 (Vicente Goser y Casellas). Contrariamente a lo pensado hasta ahora, la documentación deja muy claro que el edificio fue adquirido en 1839 por el III Marqués de Nibbiano y no por su antepasado, el célebre diplomático aragonés José Nicolás de Azara, I Marqués de Nibbiano, siendo este dato un error que se ha venido arrastrando hasta hoy. El III Marqués de Nibbiano, Agustín de Azara y Mata, había nacido en 1801 en la casa solar de los Azara en Barbuñales (Huesca), como hijo del II Marqués, Francisco Antonio de Azara, quien a su vez había heredado el título de su hermano mayor José Nicolás de Azara. A la muerte de su padre en 1820, cuando ni siquiera había llegado a la veintena, Agustín de Azara y Mata heredó el título marquesal, por lo que tuvo que casarse pronto para poder perpetuar la estirpe, algo que hizo en 1822 con M. ${ }^{a}$ Dolores López Fernández de Heredia y Azlor, hija de los Condes de Bureta. Dos años después, en 1824, nacería su primogénito, Mariano de Azara y López Fernández de Heredia, futuro IV Marqués de Nibbiano. Véase FERnÁNDEz-Mota DE Cifuentes, M. ${ }^{\text {a }}$ Teresa. Relación de títulos nobiliarios vacantes, y principales documentos que contiene cada expediente que, de los mismos, se conserva en el Archivo del Ministerio de Justicia. 2. ${ }^{a}$ edición. Madrid: Ediciones Hidalguía, 1984, p. 255. 
la portada original fue desmontada ${ }^{27}$. Por el contrario, el interior solo se remodeló, conservándose, entre otras cosas, el patio principal y la estructura tanto de la sala o salón principal como de una cámara contigua, que también mantuvieron sus dos magníficas techumbres renacentistas de casetones. En años sucesivos prosiguió la redecoración de numerosos espacios bajo la dirección de Albiñana, hasta que entre 1930-1935 se acometió una nueva reforma mucho más profunda según proyecto del arquitecto Francisco Iñiguez $\mathrm{Almech}^{28}$, que supuso la desaparición casi completa del inmueble original, ya que, entre otras cosas, el gran patio principal fue eliminado. No obstante, después de estas reformas todavía sobrevivieron las dos techumbres ya mencionadas (además de las estructuras del salón y de la estancia contigua que las albergaban), una tercera techumbre reinstalada en el nuevo zaguán y una cuarta en el rellano de la nueva escalera, así como algunas compartimentaciones de la planta noble ${ }^{29}$. En la posguerra se acometieron nuevas reformas, sobre todo en la planta baja, que acabaron de desvirtuar el edificio original. Tras la quiebra y disolución del Centro Mercantil, Industrial y Agrícola en la década de 1980, el edificio quedó en desuso, hasta que en época reciente los pocos restos del antiguo palacio, especialmente sus techumbres renacentistas, fueron puestos en valor, al igual que el resto del inmueble, tras la adquisición del edificio por una entidad bancaria, la Caja Rural de Aragón, que había decidido convertirlo en su nueva sede central. La entidad confió su restauración a un destacado arquitecto especialista en patrimonio, José María Valero Suárez, quien la proyectó en el año 2000 y dirigió su ejecución material entre 2001 y 2004 haciendo gala de una gran sensibilidad patrimonial ${ }^{30}$ [figs. 8,9 y 10 ].

27. Hoy permanece en paradero desconocido y probablemente se perdió.

28. Los diseños de la reforma fueron firmados también por los arquitectos Marrero y Sala, aunque estos no intervinieron en la ejecución material de las obras.

29. Sobre la compra del inmueble y las reformas de Albiñana e Iñiguez véase MARTíNEZ VERÓN, Jesús y Rivas Gimeno, José Luis. El Centro Mercantil de Zaragoza (1909-1935). Zaragoza: Institución "Fernando el Católico", 1985, pp. 11-37. Véase también GARCía GuATAS, Manuel. Una Joya en el Centro: un símbolo de la modernidad. Zaragoza: Caja Rural de Aragón, 2004, pp. 17-23 y 29-125.

30. Para acometer la restauración de los elementos propiamente artísticos del edificio (pinturas, relieves escultóricos, vidrieras, carpinterías decorativas...) José María Valero contó con la colaboración de la empresa Pro-Arte. Taller de Restauración de Obras de Arte S.C. de Zaragoza, dirigida por la especialista Concepción Domingo y de dilatada experiencia en la intervención en obras de arte mueble. Sobre la restauración de Valero véase García GuATAs, Manuel. Una Joya en..., op. cit., pp. 23-27 y 129. 


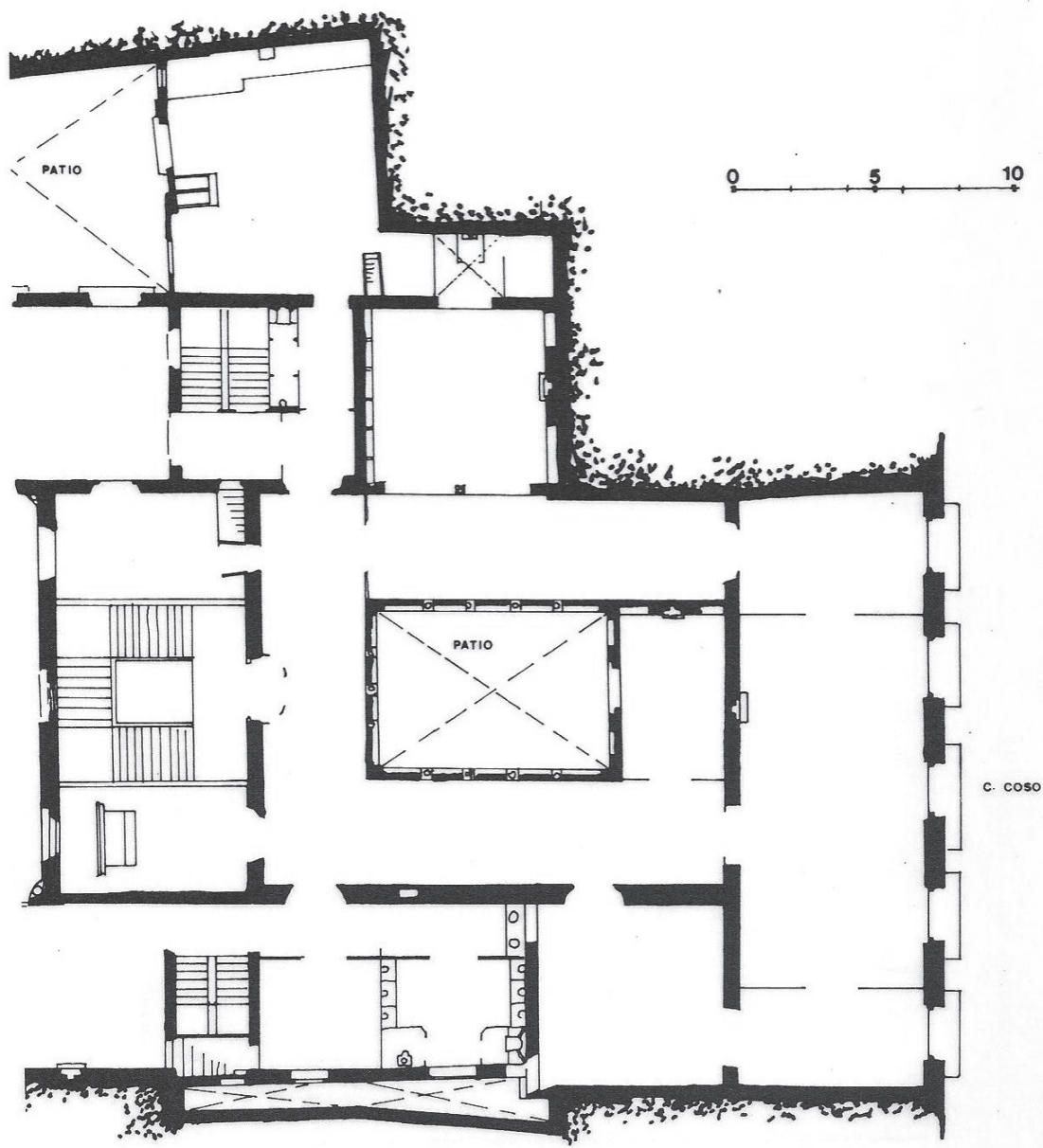

Figura 8. Planta de la zona noble del piso principal del antiguo Palacio de los Duques de Hijar en 1911, muy poco después de su compra por el Centro Mercantil, Industrial y Agrícola y justo antes de la profunda reforma de Francisco Albiñana. Dibujo adjunto al Plano Parcelario de Zaragoza de Dionisio Casañal de 1911 (AMZ, Sign. 738, Plano parcelario del Casco Histórico de Zaragoza de Dionisio Casañal de 1911). 


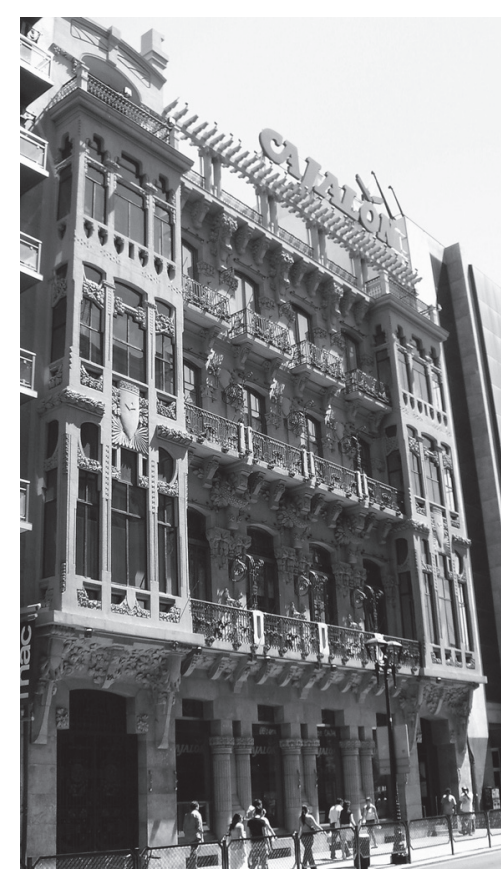

Figura 9. Vista actual de la fachada modernista diseñada por Francisco Albiñana y construida en sustitución de la antigua durante la reforma de 1912-1914.

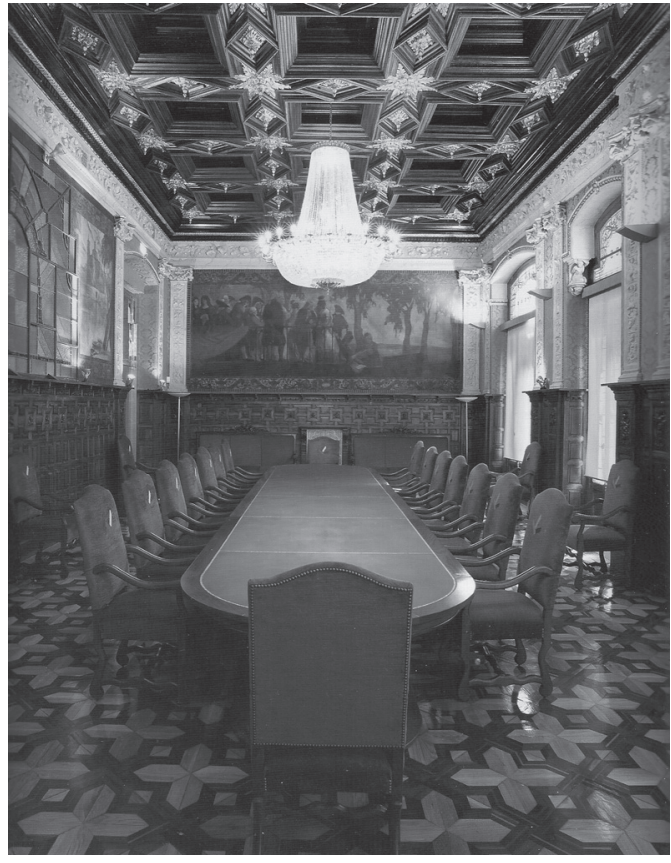

Figura 10. Vista actual del antiguo salón principal del Palacio de los Duques de Híjar, conocido posteriormente como Salón Rojo y utilizado hoy como Sala del Consejo de la Caja Rural de Aragón. Se pueden observar, entre otras cosas, la magnífica techumbre (artesonado) renacentista del primer tercio del siglo XVI, todavía conservada, y los distintos elementos ornamentales y artísticos con que se decoró el salón en las distintas reformas de la primera mitad del siglo XX.

5. Descripción y análisis del proyecto de reforma del Palacio de los DuQues DE Híjar CONCEBIDO POR Agustín SANZ. VALORACIÓN DE La PARTICIPACIÓN FALLIDA DE FRANCISCO DE GOYA

Las profundísimas transformaciones sufridas por el antiguo Palacio de los Duques de Híjar desde su adquisición por el Centro Mercantil, Industrial y Agrícola borraron por completo las huellas de las distintas intervenciones de Agustín Sanz en el edificio. Por un lado, su magnífico patio columnado de planta rectangular, que había sido salvado de la ruina por el arquitecto zaragozano, fue demolido 
AGUSTÍN SANZ Y FRANCISCO DE GOYA: EL PROYECTO DE REFORMA DEL PALACIO DE LOS DUQUES DE HÍJAR...

durante la reforma de 1930-1935, por otro, su fachada principal, reformada por Sanz hacia 1775-1776, lo fue mucho antes, en la segunda mitad de 1912, mientras que la distribución y ornamentación interior de la planta noble se vio seriamente transformada a caballo entre ambos periodos de obras, lo que impide establecer las características de la probable intervención acometida por Sanz en dicha planta al no poderse determinar su aspecto y no conservarse ni los diseños y ni el informe elaborados por el arquitecto zaragozano a finales de 1773. No obstante, la reforma en profundidad de dichos espacios interiores debió de ser concebida por Sanz, sin lugar a dudas, dentro de la sobria y refinada estética barroco-clasicista de raíz italiana, estrechamente vinculada a la escuela barroca romana, que dominaba por aquel entonces sus distintas propuestas arquitectónicas, al igual que había hecho en otras obras civiles privadas de carácter palaciego que acababa de acometer poco antes en Zaragoza, como las casas-palacio de Juan Bautista Casabona (1768-1769) y Simón Ignacio Tarazona (1770-1771) ${ }^{31}$. Así, los acabados decorativos de la zona noble del palacio los debió de concebir muy sobrios, circunscritos a detalles ornamentales muy poco excesivos (molduras perimetrales...) tendentes a realzar la prestancia de aquellos espacios del edificio en los que debía reflejarse de manera especial el buen gusto y la categoría de su ilustre propietario.

Por el contrario, sí que se puede conocer el aspecto y la configuración aproximada que dio Agustín Sanz a la fachada principal del palacio, que se abría a la amplia calle del Coso, gracias a varias fotografías de finales del siglo XIX y principios del XX que la muestran antes de su desaparición. Concretamente, se observa que dicha fachada, caracterizada por una gran sobriedad de líneas y una austeridad formal muy marcada, presentaba un gran zócalo, aparentemente de sillería, que abarcaba la altura de la planta calle y el entresuelo, plantas que se articulaban respectivamente mediante sendas parejas de puertas-escaparate y ventanas, situadas a los lados de la magnífica portada renacentista, que destacaba por su marcado clasicismo al estar inspirada en el aspecto que presentaba el Arco de Tito de Roma antes de su restauración arqueológica, debida a los arquitectos neoclásicos Raffaele Stern y Giuseppe Valadier y acometida en 1818-1821, y en ciertos detalles del Arco de Constantino, también de Roma. Dicha portada se ubicaba en el centro de la fachada, marcando su eje central y delimitando el límite superior del zócalo, ya que abarcaba la altura de la planta baja y el entresuelo. Por encima se desarrollaban otras dos plantas alzadas. La principal o noble, de gran altura, se abría al exterior mediante cinco magníficos balcones adintelados con sus antepechos de barrotes sencillos de hierro forjado típicamente dieciochescos, todos los cuales correspondían a la sala o salón principal del palacio, que abarcaba íntegramente la anchura de la fachada, un caso excepcional entre los grandes palacios

31. Sobre estas dos casas-palacio véase: MARTínez Molina, Javier. La Casa-palacio de Simón Ignacio Tarazona..., op. cit., pp. 475-496; y MARTínez MOLINA, Javier. Juan Bautista Casabona, un indiano..., op. cit., pp. 101-128. 
AGUSTÍN SANZ Y FRANCISCO DE GOYA: EL PROYECTO DE REFORMA DEL PALACIO DE LOS DUQUES DE HÍJAR..

renacentistas zaragozanos ${ }^{32}$. La segunda planta, la última del inmueble, se desarrollaba justo por debajo del magnífico y saliente alero renacentista de madera tallada que coronaba el conjunto de manera efectista, que se había mantenido por su gran calidad, configurándose mediante otros cinco vanos abalconados alineados con los inferiores aunque de mucha menor altura y anchura y de antepechos de menor vuelo pero dotados de nuevo de barrotes sencillos de hierro forjado. Tanto los vanos abalconados de la planta noble como los del piso superior presentaban sus perfiles resaltados con una sencilla moldura clasicista que se destacaba sobre la superficie enlucida de la fachada, que a finales del siglo XIX carecía de pinturas murales y se cubría mediante un simple despiezado que imitaba sillares de piedra, mientras que en los primeros años del XX estaba decorada mediante grandes esgrafiados de estética modernista [figs. 11 y 12].

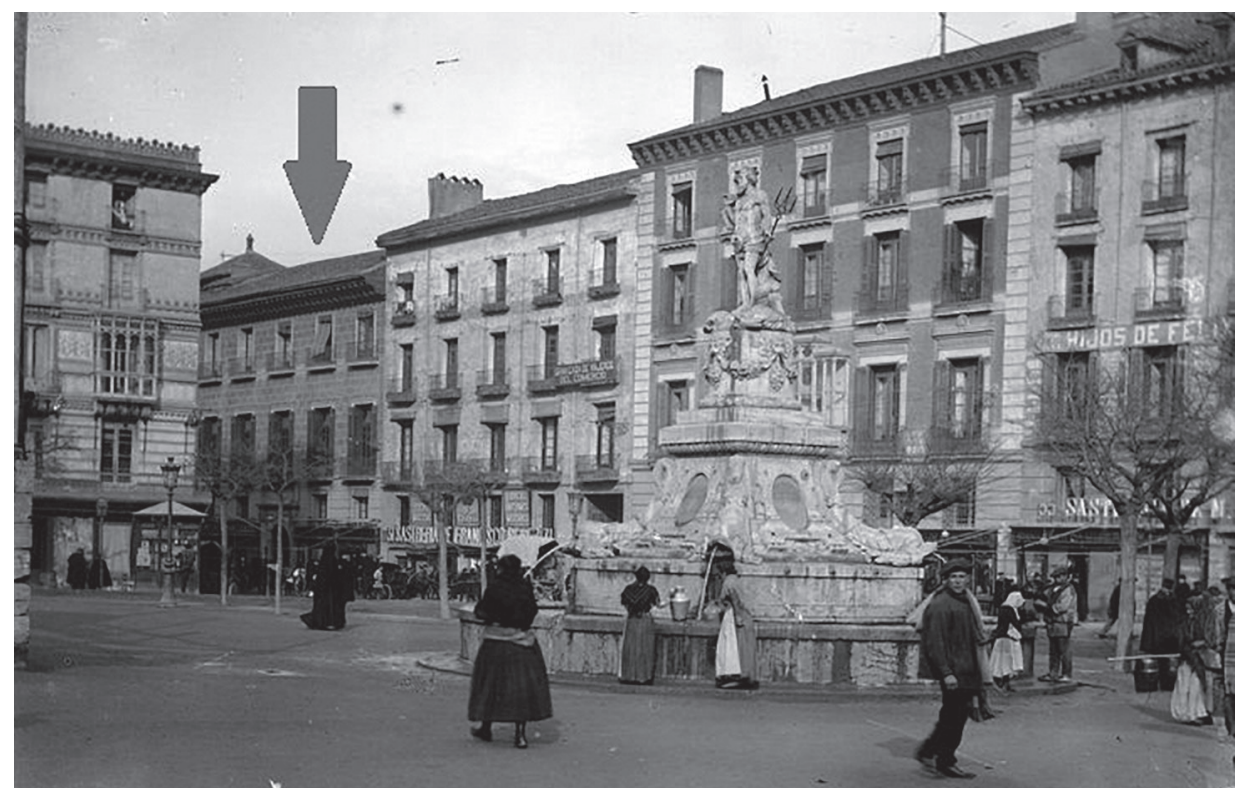

Figura 11. Vista de la actual plaza de España de Zaragoza en el tránsito entre los siglos XIX y XX. A la izquierda se observa la fachada principal del antiguo Palacio de los Duques de Híjar, recayente a la calle del Coso. Dicha fachada, que quedaba coronada y protegida por un monumental alero renacentista de madera, presentaba entonces su superficie enlucida simulando un despiezado de grandes sillares.

32. Gómez Urdáñez, Carmen. Arquitectura civil en Zaragoza en..., op. cit., pp. 185-186. La magnífica techumbre renacentista de dicha sala y las propias dimensiones de dicho espacio aún se conservan gracias a que su estructura mural se mantuvo, aunque redecorada, en las distintas reformas del siglo XX. 


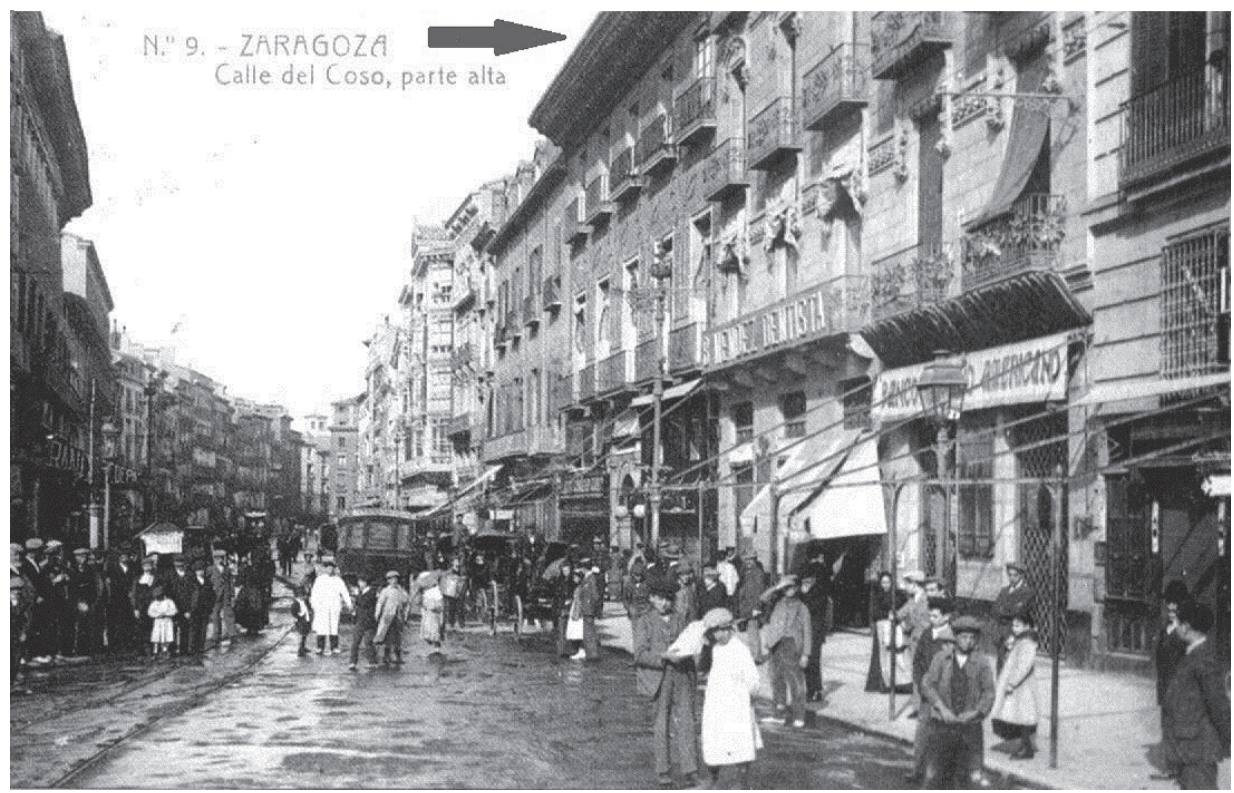

Figura 12. Vista general de la calle del Coso de Zaragoza en los primeros años del siglo XX. A la derecha se observa la fachada principal del antiguo Palacio de los Duques de Híjar, que quedaba cobijada por su monumental alero renacentista de madera y que presentaba su superficie decorada ya con vistosos esgrafiados modernistas.

Buena parte de la configuración y ordenación de huecos que presentaba la fachada a finales del siglo XIX correspondía a mi juicio a la reforma diseñada por Agustín Sanz a finales de 1773 y ejecutada hacia 1775-1776, atendiendo a sus indudables características dieciochescas y al hecho de que no exista constancia documental de haberse acometido reforma alguna de envergadura en el inmueble en el periodo 1738-1774 (ningún maestro de obras zaragozano declaró haberlo reedificado en dicho periodo), y dado que Sanz fue el arquitecto de referencia del Duque de Hijar en Aragón entre 1765 y 180133. De hecho, la estricta ordenación de los vanos, su disposición simétrica y compensada, sus proporciones armoniosas, su enmarcamiento sencillo etc., son características típicas de la arquitectura civil zaragozana del último tercio del siglo XVIII y especialmente de aquella desarrollada por Sanz, que se distinguía además por una gran sobriedad de líneas y un despojamiento decorativo muy marcado, rasgos también presentes aquí que

33. AMZ, Serie Facticia, Caja 6, Sign. 12 (o Caja 6.955), Relación de casas construidas en Zaragoza a efectos de contribución por los distintos maestros de obras entre 1738 y 1765 , y entre 1766 y 1774 . 
entroncaban a la perfección con los principios estéticos de raíz funcionalistarigorista predominantes en el campo de la arquitectura civil en la época de la Ilustración, pero también con la tradicional austeridad exterior de la arquitectura aragonesa, dos realidades que Sanz conocía bien.

A mi juicio, Agustín Sanz reordenó la fachada e hizo nuevos los huecos de la planta baja y el entresuelo que, probablemente, al igual que ocurrió en el caso de otros palacios renacentistas, debieron de ser en origen, y sobre todo con el paso del tiempo, de ordenación un tanto anárquica, cerrándose sin duda con rejas buena parte de ellos. En la planta noble la intervención debió de ser de menor envergadura dado que sus cinco vanos eran ya abalconados en $1773^{34}$, aunque probablemente fueron ampliados, siendo sustituidos sus antepechos y añadiéndose entonces sus sencillas y clasicistas molduras perimetrales. En claro contraste, la reordenación de los huecos de la planta segunda fue mucho más ambiciosa, ya que se eliminó el monumental mirador o galería de arquillos original, que correspondía a la antigua falsa, espacio diáfano y ventilado situado bajo la cubierta típico de la arquitectura civil renacentista aragonesa ${ }^{35}$, dado que había dejado de cumplir su función original meramente estética al usarse dicha planta, ya desde hacía tiempo, no como un espacio residual sino como un lugar de habitación destinado a la servidumbre principalmente ${ }^{36}$. Ese cambio de uso de la falsa, que fue general en muchos edificios zaragozanos de la época, junto al desfase estético de los típicos miradores aragoneses respecto al gusto dieciochesco, muy propenso al uso generalizado de balcones, motivó la eliminación de los arquillos para dar lugar a unos vanos abalconados acordes con la nueva funcionalidad de las estancias situadas detrás, práctica que fue frecuente en la arquitectura palaciega zaragozana del último tercio del siglo XVIII, como lo indica el que cuatro de los principales palacios de la ciudad cuyas fachadas fueron reformadas en profundidad o rehechas por completo en dicho periodo, algunas bajo diseño probable de Sanz (el Palacio de Domezayn, de la Marquesa de Estepa o de Tarín, el Palacio de los Condes de Sobradiel en 1771-1772, el Palacio de los Marqueses de Lazán en 1785, y el Palacio de los Marqueses de Ayerbe en 1789-1792), vieron sustituidos sus antiguos arquillos por grandes ventanas o amplios balcones.

En cuanto a su acabado superficial, a finales del siglo XIX la fachada principal, al igual que en su origen y que en el último tercio del siglo XVIII, estaba

34. AHPZ, ADH, Sala II, Leg. 147, Doc. 9.2. Respuestas a Su Excelencia, 1773 (Carta de 28-IX1773).

35. La existencia en origen de la galería de arquillos está perfectamente documentada. Véase Gómez URdáñez, Carmen. Arquitectura civil en Zaragoza en..., op. cit., pp. 184-185.

36. A principios de la década de 1770 había diversas habitaciones o apartamentos habitados en el interior del palacio, ocupados por lo que parecían ser sirvientes o antiguos empleados de la Casa Ducal de Híjar, que se debían de concentrar fundamentalmente en la planta baja, los entresuelos y el piso superior. También cabe la posibilidad de que alguno fuera de alquiler con el fin de sacar rentabilidad al inmueble. 
AGUSTÍN SANZ Y FRANCISCO DE GOYA: EL PROYECTO DE REFORMA DEL PALACIO DE LOS DUQUES DE HÍJAR...

enlucida. No obstante, me ha sido imposible determinar si llegó a decorarse con pinturas murales de otro artista que no fuera Francisco de Goya, aunque todo parece indicar que no, ya que de lo contrario este hecho, por su especial singularidad, hubiera sido reseñado por un personaje tan amante de la anécdota y el dato curioso como Faustino Casamayor, cronista oficioso de la Zaragoza de finales del siglo XVIII y las primeras décadas del XIX, o incluso por el célebre abate Ponz, que tras visitar la ciudad hizo una breve alusión al palacio en el tomo dedicado a Aragón de su Viage de España, publicado en 1788 ${ }^{37}$. Probablemente, la fachada se enlució de nuevo con el fin de uniformizar las superficies antiguas y las reformadas, y después fue pintada con un único color, sin duda de gran viveza, siguiendo la moda vigente en la Corte por aquel entonces.

Obviamente, es imposible determinar el aspecto concreto que hubieran tenido las pinturas murales de fachada de Francisco de Goya, ya que no se llegaron a ejecutar. Muy probablemente, el pintor aragonés ni siquiera llegó a elaborar bocetos de la obra dado que no se le llegó a hacer un encargo en firme antes de su marcha a Madrid a principios de enero de 1775 ante la determinación del duque de dilatar su decisión definitiva sobre la reforma del palacio. Sin la firmeza de un encargo, Goya no estaba en condiciones de dedicarse a elaborar bocetos, dado que en 1774 estaba muy ocupado en la terminación de las pinturas murales de la Iglesia de la Cartuja de Aula Dei y debía concentrar sus atenciones en obtener nuevos encargos seguros de cierta envergadura dado que debía mantener a su familia, sobre todo teniendo en cuenta que su primer hijo estaba en camino (de hecho, nació el 29 de agosto de 1774, cuando estaba en plena finalización de las pinturas de Aula Dei). Eso explicaría que Goya aceptara sin dudarlo la oferta del primer Pintor de Cámara del rey Carlos III, el gran Anton Rafael Mengs, para ser su colaborador en la Real Fábrica de Tapices de Santa Bárbara elaborando cartones para tapices, lo que suponía un gran paso adelante en sus altas aspiraciones profesionales, y que en pleno invierno, a la conclusión de las pinturas cartujanas, decidiera marchar hacia Madrid a pesar de los peligros que el tortuoso viaje, que duraba en torno a una semana, conllevaba para él y su familia (nevadas...), sobre todo para su hijo Antonio, de apenas cuatro meses de vida ${ }^{38}$.

No obstante, que Francisco de Goya no llegara a elaborar bocetos no quiere decir a mi juicio que no tratara con Agustín Sanz la posible temática, la iconografía y la composición de las pinturas para la fachada del Palacio de los Duques de Híjar. Cabe la posibilidad incluso de que Sanz, dada su meticulosidad y precisión, llegara a incluir en el dibujo que elaboró para el duque mostrando su propuesta de reforma de la fachada, fruto de sus conversaciones con el pintor aragonés, alguna representación esquemática y aproximativa del tipo de pinturas que Goya y él habían acordado acometer en caso de que el proyecto saliera adelante. Sin

37. Ponz, Antonio. Viage de..., op. cit., p. 79.

38. ANSÓn NAVARro, Arturo. Goya y Aragón..., op. cit., pp. 107-118. 
duda, dichas pinturas no serían de tipo meramente decorativo y anecdótico (guirnaldas, decoración vegetal, escudos), ya que en ese caso no sería necesario encargarlas a un artista de la valía de Goya, que ya a finales de 1773 era el mejor pintor activo en Zaragoza y el que más cotizaba, sino a un mero pintor-decorador, que por mucho menos dinero cumpliría eficazmente con el trabajo. Además, Goya, en caso de acometer pinturas murales de fachada, que consideraba un tipo de obra menor, querría lucirse, para lo que sin duda exigiría poder llevar el encargo a su terreno, es decir, realizar pintura "de figuras», que era mucho más valorada («el auténtico pintor» acometía escenas con figuras humanas y no solo paisajes o arquitecturas), renunciando a lo convencional y desarrollando en exteriores un tipo de pintura mural más o menos equiparable a la que había practicado en interiores como la bóveda del Coreto del Pilar (1771) o a la que estaba ejecutando en la Cartuja de Aula Dei.

Así, dentro de las peculiaridades de la pintura "de figuras» y atendiendo al tipo de comitente, un Grande de España perteneciente a uno de los linajes más encumbrados y antiguos de la nobleza española, el tipo de representación pictórica más factible para la fachada del palacio ducal sería, sin duda, algún tipo de programa alegórico complejo tendente a exaltar el linaje de los Híjar a través de aspectos como sus grandes personajes, su historia o sus actividades, o mediante aquellos conceptos universales (valor, honor, justicia...) que se suponían a los miembros de un linaje tan encumbrado. No obstante, las escenas de carácter figurativo, que podrían ser alegóricas o incluso narrativas, y que se desarrollarían en los amplios netos de la fachada entre vano y vano y entre los pisos, irían acompañadas, aunque solo como ambientación o complemento, de elementos meramente decorativos como: pilastras, frontones, entablamentos, guirnaldas, escudos, ornamentaciones vegetales etc., aunque en algunas zonas podrían existir fondos de paisaje más complejos, tanto naturales como urbanos, o incluso algún tipo de trampantojo arquitectónico, algo en lo que sin duda colaboraría Agustín Sanz.

A pesar de que hoy pueda no parecerlo por la desaparición de buena parte de los ejemplares más destacados, la pintura mural de fachada era una modalidad pictórica muy extendida, por influjo italiano, en la España dieciochesca, aplicándose sobre todo a la arquitectura civil residencial de alto nivel, especialmente en zonas como Andalucía o el área mediterránea (Cataluña, Valencia, Murcia) ${ }^{39}$, donde la influencia italiana se dejaba sentir con mayor intensidad, y mucho menos en las dos Castillas o en las regiones del Norte. No obstante, para hacerse una cierta idea del tipo de pintura mural que Agustín Sanz y Francisco de Goya habrían pensado para el Palacio de los Duques de Híjar no es necesario alejarse mucho de Zaragoza ya que en el propio Aragón, en la actual provincia de Huesca, existen

39. En el área mediterránea fueron muy frecuentes también, como sustitutivo de las pinturas murales de fachada, los esgrafiados, muy adecuados cuando la decoración debía ser meramente ornamental y de carácter repetitivo o seriado, ya que permitían soluciones muy efectistas a bajo coste. 
AGUSTÍN SANZ Y FRANCISCO DE GOYA: EL PROYECTO DE REFORMA DEL PALACIO DE LOS DUQUES DE HÍJAR...

varios ejemplos muy notables de pinturas murales de fachada dieciochescas aplicadas a edificios civiles de carácter residencial que, muy probablemente, responden, salvando las evidentes distancias en cuanto a calidad y modernidad estética, a una idea similar a la que pudieron concebir Sanz y Goya. Dichos ejemplos se concentran en la magnífica plaza mayor porticada de la localidad de Graus, siendo uno de los casos más destacables el de la Casa-palacio de los Heredia, actual sede del Consejo Comarcal de la Ribagorza, cuyas pinturas, fechables según Arturo Ansón en torno a 1785, son de dos tipos: de carácter meramente decorativo entre los vanos de la fachada principal (pilastras y columnas fingidas, entablamentos, tallos vegetales, guirnaldas, tornapuntas, veneras, un reloj de sol...) y de tipo narrativoalegórico en los cajeados del amplísimo y saliente alero en caveto o de gola, donde se representaron, entre pequeñas pilastras, siete escenas de la parábola del hijo pródigo (en la zona central) y cuatro alegorías de las estaciones del año (en los extremos), todas ellas bien resueltas dentro de una sensibilidad todavía rococó ${ }^{40}$ [figs. 13 y 14].

También muy interesantes son las pinturas de otro inmueble de la plaza mayor de Graus, la Casa-palacio del Barón, antigua residencia de los Barones de Abella de la Conca, fechables en el último cuarto del siglo XVIII y probablemente parecidas, a grandes rasgos, a las que Agustín Sanz y Francisco de Goya pretendían desarrollar en el Palacio de los Duques de Hijar, dado que la fachada principal de este edificio se orna en su zona central con dos grandes composiciones figurativas superpuestas: las representaciones de las Alegorías de las Artes y de las Ciencias respectivamente, que se insertan en dos grandes recuadros de fondo ocre-amarillo enmarcados a modo de quadri riportati, mientras que el resto de la superficie

40. Ansón NAVARro, Arturo. "El arte barroco en la Ribagorza». En Valle Melendo, Javier del y Espona Vila, José (coords.). Comarca de La Ribagorza. Zaragoza: Gobierno de Aragón, 2006, pp. 189-195, espec. pp. 194-195. La Casa Heredia era la antigua residencia de la familia infanzona de los Heredia, algunos de cuyos miembros jugaron un destacado papel durante la Ilustración, como el ilustre diplomático Ignacio de Heredia y Alamán (1728-1792), secretario y mano derecha del Conde de Aranda durante más de cinco lustros (durante catorce años fue el Secretario de la Embajada española en París a las órdenes de Aranda y, enviado por este a Londres, preparó las negociaciones de la Paz de Versalles), o su hermano el catedrático de jurisprudencia de la Universidad Sertoriana de Huesca, Vicente de Heredia y Alamán, también naturalista, geógrafo y pionero del pirineismo, que fue sin duda el impulsor de la profunda reforma de la casa hacia principios de la década de 1780, reforma que culminó con la realización de las efectistas pinturas murales de su fachada en torno a 1785. Fue el impulsor más que probable de dicha reforma ya que heredó el mayorazgo familiar a comienzos de la década de 1780, a la muerte de su padre, lo que le obligó a abandonar la cátedra, a instalarse en Graus y a casarse, algo que hizo en mayo de 1786 con Josefa Godino y Lobera, natural de Ateca (Zaragoza). Su asentamiento en Graus y su inminente boda pudieron ser un buen motivo para la reforma en profundidad de la casa familiar, algo que parece quedar corroborado por el hecho de que la cronología de estos acontecimientos coincida con la que es atribuible a las pinturas que decoran la fachada desde un punto de vista estilístico, formal e iconográfico. Sobre Ignacio y Vicente de Heredia véase OlaEchEa ALBISTUR, Rafael. "Ignacio de Heredia y su biblioteca». Revista de Historia Moderna, 1984, 4, pp. 211-291 (sobre Vicente de Heredia véase espec. pp. 258-260). 


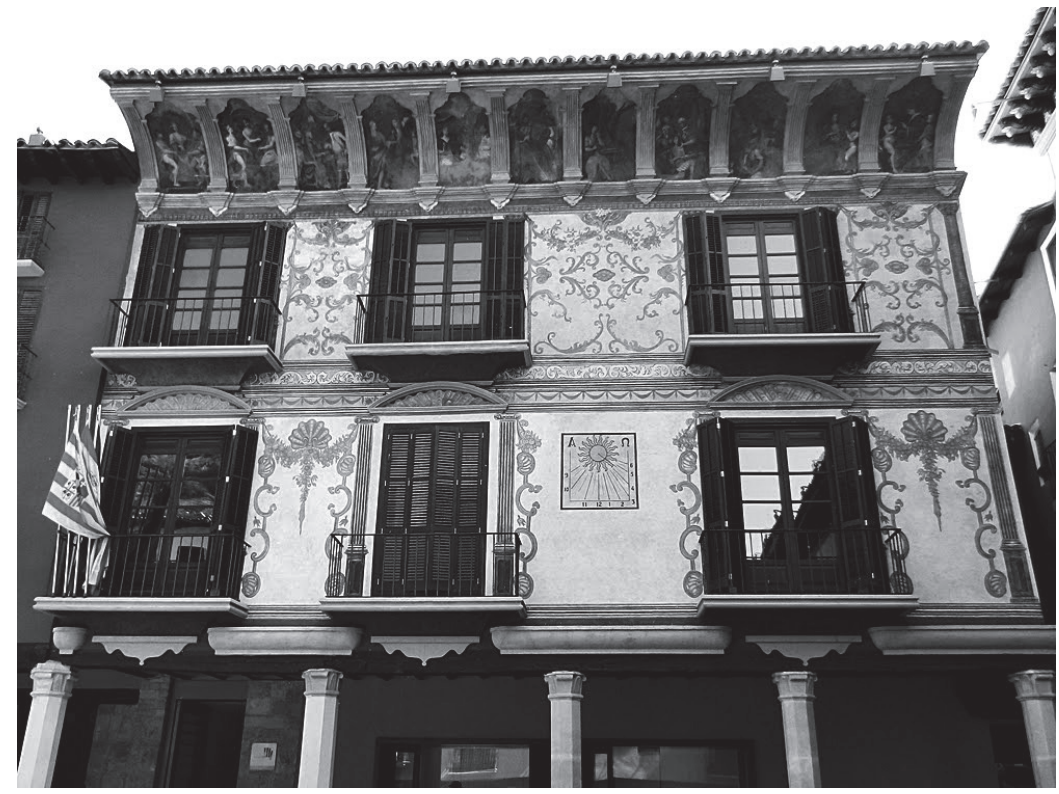

Figura 13. Vista general de la fachada principal de la Casa-palacio de los Heredia de Graus (Huesca) en la actualidad. Se pueden observar sus interesantes pinturas murales dieciochescas.

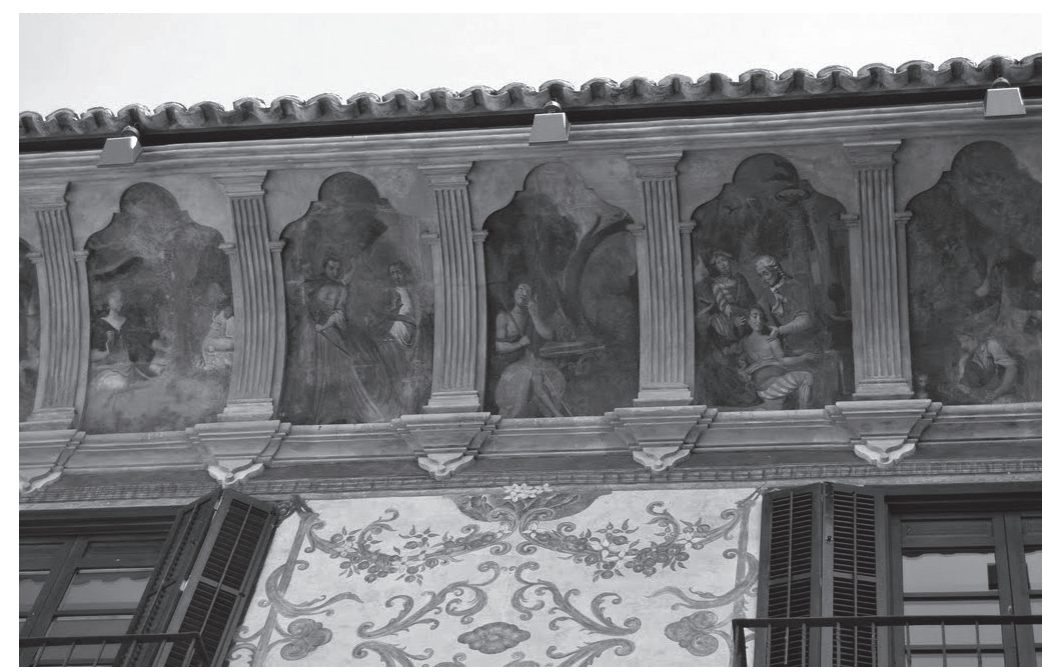

Figura 14. Detalle de las pinturas murales dieciochescas del alero en caveto o de gola de la fachada principal de la Casa-palacio de los Heredia de Graus (Huesca). 
AGUSTÍN SANZ Y FRANCISCO DE GOYA: EL PROYECTO DE REFORMA DEL PALACIO DE LOS DUQUES DE HÍJAR...

mural se decora, sobre un fondo rojo general, con todo un repertorio pintado de carácter ornamental a base de arquitecturas fingidas (pilastras, cajeados, bandas), cenefas, guirnaldas vegetales, motivos de cueros recortados, tornapuntas, retratos en tondos etc., sobre todo en torno a los vanos o remarcando la separación entre los pisos ${ }^{41}$ [figs. 15 y 16].

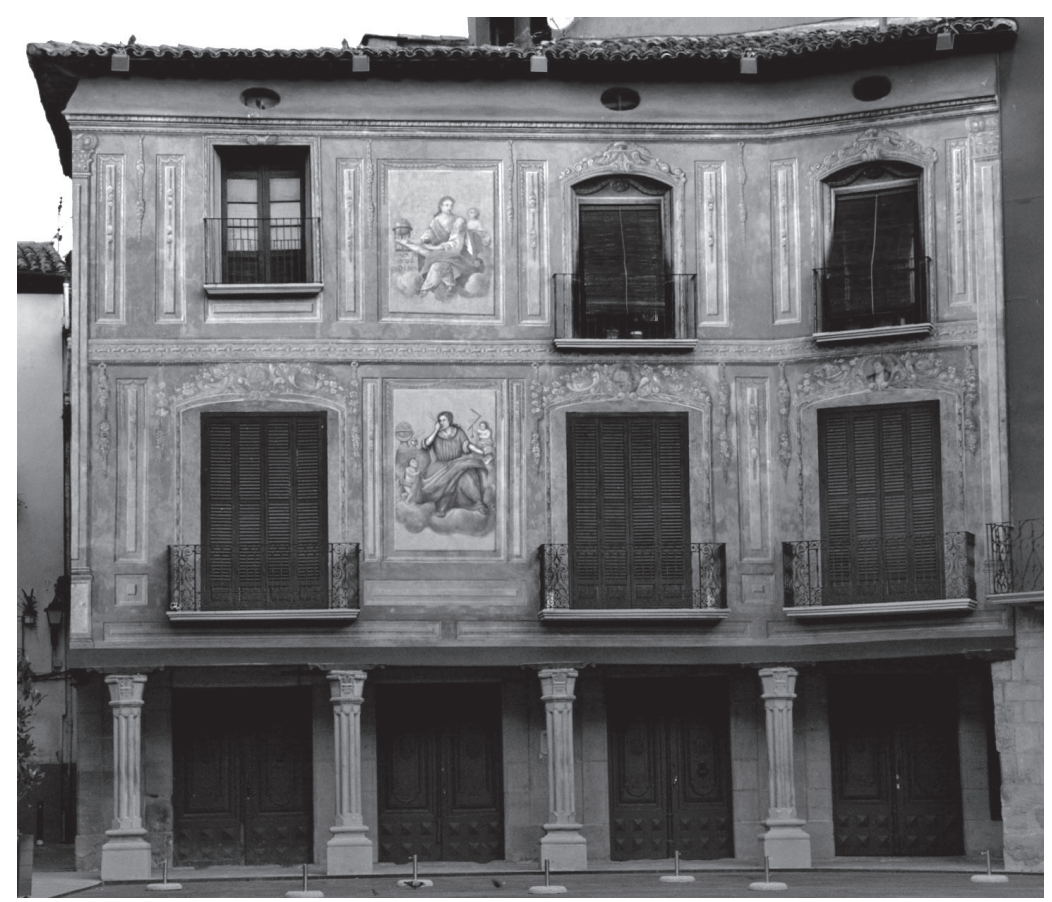

Figura 15. Vista general de la fachada principal de la Casa-palacio del Barón de Graus (Huesca). Destacan sus efectistas pinturas murales dieciochescas.

41. AnSÓn NAVARro, Arturo. El arte barroco..., op. cit. p. 194. La Casa del Barón o de Pentineta, de origen medieval, debe su nombre al catalán Antonio de Subirá y Codol (fallecido el 14-VII-1811), Barón de Abella de la Conca, propietario del inmueble y residente en él a finales del siglo XVIII, e impulsor probable de su reforma y de la realización de sus pinturas murales, fechables en el último cuarto del siglo XVIII. Dichas pinturas destacan por su gran efectismo todavía barroco y, sin duda, dado su carácter poco frecuente a nivel aragonés, debieron de causar en su momento gran sensación en la comarca. Según una leyenda local, el mencionado noble mandó decorar las fachadas de su casa con pinturas murales de vivos colores para contentar a su mujer, originaria, según la tradición, de Andalucía, donde este tipo de decoraciones eran mucho más frecuentes, sobre todo en Málaga y Granada. Nada más lejos de la realidad, ya que Subirá estaba casado con una Heredia, Manuela de Heredia, grausina y hermana menor de Vicente e Ignacio de Heredia. Véase OlaEchEa Albistur, Rafael. Ignacio de Heredia..., op. cit., p. 258. 


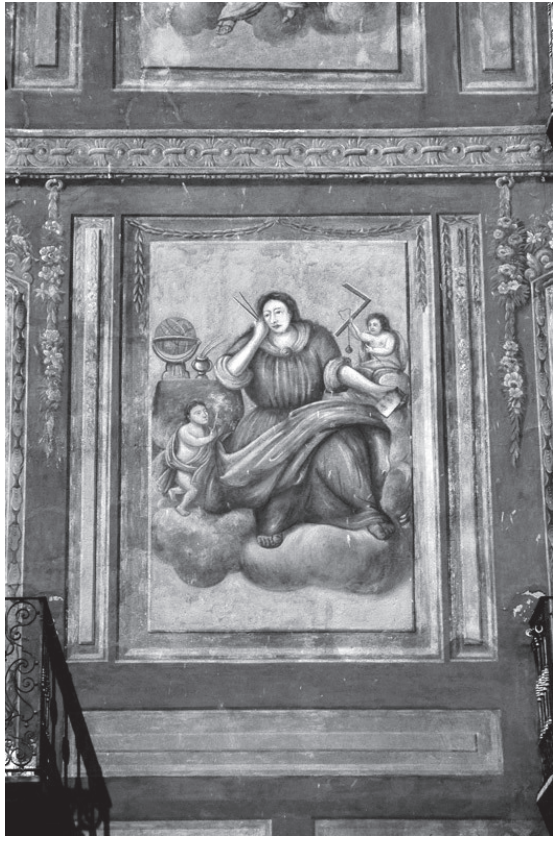

Figura 16. Vista de la Alegoría de las Ciencias que decora la fachada principal de la Casa-palacio del Barón de Graus (Huesca), que se complementa con una Alegoría de las Artes situada encima.

\section{EPÍLOGO}

El proyecto de reforma del Palacio de los Duques de Híjar en Zaragoza fue un jalón más en la estrecha e intensa relación comitente-artista establecida entre el IX Duque de Híjar y Agustín Sanz desde principios de 1765 , relación que se extendió hasta el fallecimiento de este último en el verano de 1801. Precisamente, la década de 1770 fue la época más álgida de la vinculación entre ambos, ya que fue entonces cuando el arquitecto aragonés acometió el diseño y construcción de los dos edificios más relevantes que le encomendó el duque en sus 36 años de relación profesional: las nuevas iglesias parroquiales de Urrea de Gaén y Vinaceite, concluidas ya a comienzos de la década de 1780, que constituyeron dos de las cimas de su producción arquitectónica y que le proporcionaron gran fama, apuntalando el enorme prestigio que había alcanzado ya desde principios de los 70 gracias a encargos tan relevantes como la nueva Parroquial de la Exaltación de la Santa Cruz de Zaragoza, cuya construcción dirigió entre 1773

y 1780. Con todo, como ya se ha señalado, el proyecto de reforma del palacio ducal no pudo ser una obra plenamente satisfactoria al no poderse contar finalmente con la intervención de Francisco de Goya en la decoración de la fachada, un deseo muy anhelado por su gran amigo Agustín Sanz que, con la maestría de los pinceles del pintor de Fuendetodos, quería conseguir un edificio de gran efectismo y novedad en el ámbito zaragozano que fuera fiel reflejo de la distinción y buen gusto de su comitente. 
